\title{
The (in)elasticity of moral ignorance
}

by Marta Serra-Garcia and Nora Szech

No. 120 | DECEMBER 2018

\section{WORKING PAPER SERIES IN ECONOMICS}

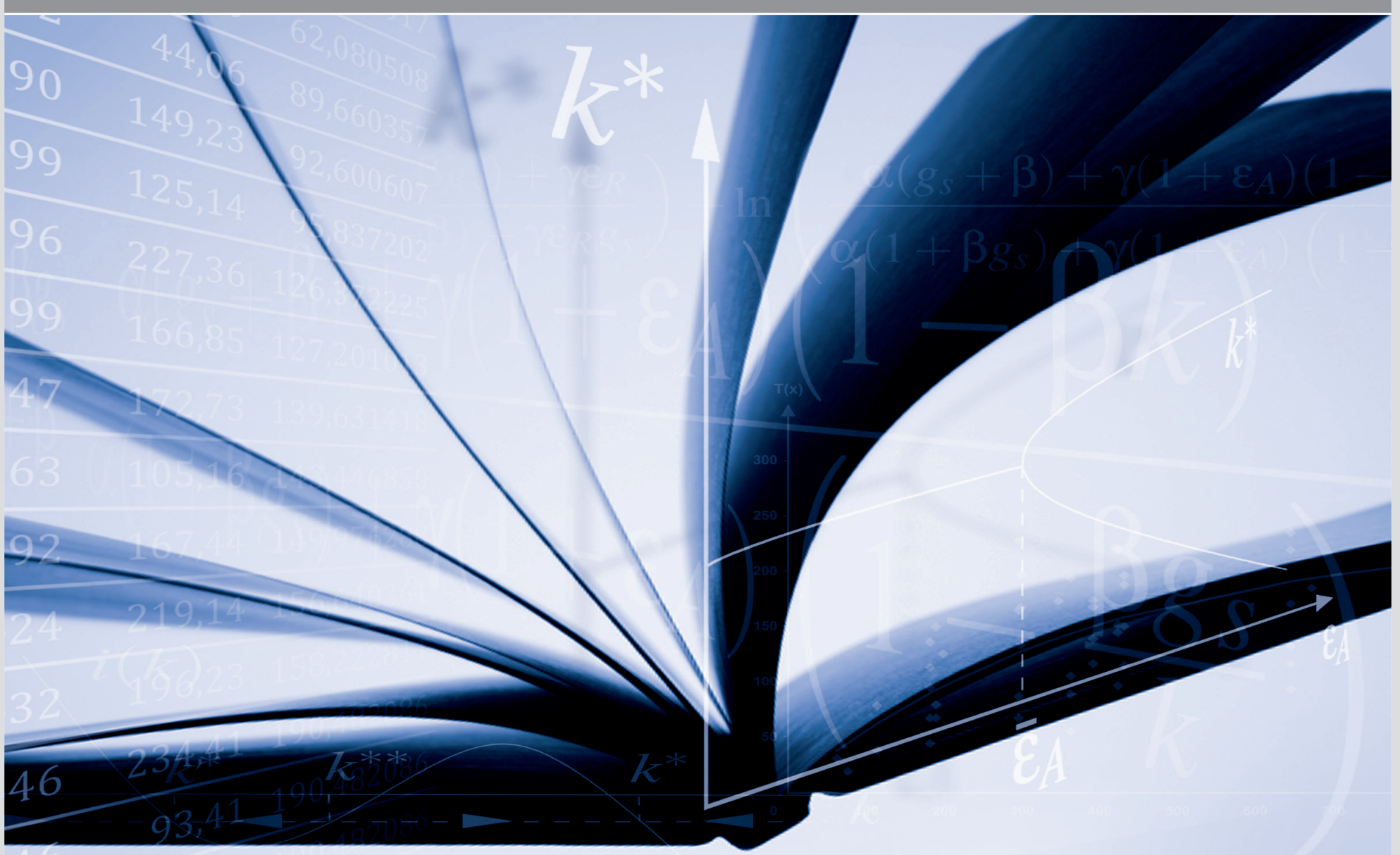




\section{Impressum}

Karlsruher Institut für Technologie (KIT)

Fakultät für Wirtschaftswissenschaften

Institut für Volkswirtschaftslehre (ECON)

Kaiserstraße 12

76131 Karlsruhe

KIT - Die Forschungsuniversität in der Helmholtz-Gemeinschaft

Working Paper Series in Economics

No. 120, December 2018

ISSN 2190-9806

econpapers.wiwi.kit.edu 


\title{
The (In)Elasticity of Moral Ignorance*
}

\author{
Marta Serra-Garcia ${ }^{\dagger}$ and Nora Szech ${ }^{\ddagger}$
}

December 2018

PRELIMINARY VERSION. COMMENTS WELCOME.

\begin{abstract}
We investigate the elasticity of preferences for moral ignorance with respect to monetary incentives and social norm information. We propose a model where uncertainty differentially decreases the moral costs of unethical behavior, and benchmark the demand curve for moral ignorance against a morally neutral context. In line with the model, selfishness is a main determinant of moral ignorance, and the demand curve for moral ignorance is highly elastic when information shifts from being costly to incentivized. Moral ignorance is considered morally inappropriate. Providing this information increases moral behavior but does not shift the demand curve for ignorance.
\end{abstract}

JEL Classification: D83; D91; C91.

Keywords: Information avoidance, morality, unethical behavior, social norms.

*We would like to thank Sandro Ambuehl, Dorothea Kübler, Jeff Naecker, Sally Sadoff, Nikolaus Schweizer, Charlie Sprenger, Jeroen van de Ven, Joël van der Weele and the audiences at the University of Basel, University of Innsbruck, the HeiKaMax Workshop, the 2018 Communication Workshop at the University of Amsterdam, and the 2018 Science of Philanthropy conference for helpful comments and suggestions. We would also like to thank Anke Greif-Winzrieth, Nicola Hüholt, and Giulia Maimone for excellent research assistance, and Sibille Hackel for administrative support.

${ }^{\dagger}$ Rady School of Management, UC San Diego and CESifo. Email: mserragarcia@ucsd.edu.

$\ddagger$ Department of Economics, Karlsruhe Institute of Technology (KIT), Berlin Social Science Center (WZB), and CESifo. Email: nora.szech@kit.edu 


\section{Introduction}

Information avoidance allows individuals to engage in questionable ethical behavior. Consumers ignore production standards involving child labor or environmental damage, and even denigrate consumers who seek information in order to identify more ethical products (Zane et al., 2016). Many art collectors and museum managers ignore the origins of potentially stolen art work. ${ }^{1}$ Managers avoid information about potentially unethical behavior taking place at their companies (e.g., Rayner, 2012). ${ }^{2}$ Also in simple moral dilemmas, individuals avoid costless information about the consequences on their choices for others, thereby inducing "moral wiggle room" to act selfishly (e.g., Dana et al., 2007; van der Weele, 2014; Bartling et al., 2014; Grossman, 2014; Grossman and van der Weele, 2017; Freddi, 2017; Golman et al., 2017, for a review).

Due to the societal costs of moral ignorance, understanding the nature of preferences for moral ignorance is important. In this paper we study the elasticity of moral ignorance. We first examine the elasticity of moral ignorance with respect to the monetary cost to acquire or avoid information, and for the first time benchmark it against a morally neutral context. Our results show that the demand curve for information exhibits a sharp kink when moving from small monetary costs to small incentives to acquire information about an uncertain moral dilemma. Hence, ignorance can be reduced by more than 50 percent at a small cost. We next examine a completely costless approach, based on the idea of "moral reminders" (OECD, 2018), that uses social norms to manipulate the moral costs of ignorance. Most subjects consider moral ignorance and selfishness morally inappropriate. However, while norm information decreases the likelihood of selfish acts, it has little impact on the demand for moral ignorance. Our results suggest that norm provision not only increases how much people care about a morally relevant situation, but also how bad some feel if they decide to act selfishly nevertheless. These findings suggest that preferences for moral ignorance exhibit unique properties that are distinct from other moral behaviors.

\footnotetext{
${ }^{1}$ For example, "The World Jewish Congress (WJC), a New York-based advocacy group, has criticized museums for waiting for artworks to be claimed by Holocaust victims instead of publicly announcing that they have suspect items" (Source: CNN.com, March 2, 2000).

${ }^{2}$ For example, Martin Winterkorn, former CEO of Volkswagen AG, argued that he would have stopped the emissions scandal if only he had known about it earlier. Yet investigations suggest that Winterkorn could have known already in 2007 (Source: USA Today, Jan. 19, 2017). In general, in large organizations, a manager's ability to know about other individual's ethical behavior may be conveniently limited (Jackall, 1988; Dana, 2006).
} 
To study preferences for moral ignorance, we develop a new experimental paradigm, the "envelope game". In this game, an individual chooses between an envelope that may contain a donation or nothing and a certain, private payment. We measure demand for information, by allowing the individual to learn (or avoid learning) the envelope's content before choosing between the envelope and the selfish option. Opening the envelope or leaving it closed is monetarily incentivized.

A rich literature documents that individuals often seek excuses to avoid charitable giving and other prosocial behaviors. They avoid the charitable ask (e.g., DellaVigna et al, 2012; Andreoni et al., 2017; Exley and Petrie, 2018), and use risk (Exley, 2015) or employ information about poor charity performance (Exley, 2017) as excuses not to donate. Moreover, anecdotal evidence suggests that individuals ignore information about charity performance and put forward scandals surrounding the high administrative costs and executive salaries of some charities as excuses not to give at all. ${ }^{3,4}$ Yet, recent surveys by Golman et al., (2017) and Hertwig and Engel (2016) demonstrate that ignorance does not only occur in morally relevant situations, but in a variety of contexts, such as health (Oster et al., 2013; Ganguly and Tasoff, 2016), portfolio investment decisions (Karlsson et al., 2009; Sicherman et al., 2016), or work situations (Huck et al., 2018). Therefore, in this paper we disentangle how much ignorance is driven by the moral relevance of a situation, above and beyond other, morally neutral aspects.

Traditional models of altruism predict that individuals should not forego money in order to remain ignorant when the envelope contains a potential donation, as rejecting a charitable donation is not assumed to induce any moral costs. Yet, recent evidence has shown that individuals often exhibit costs from rejecting a donation opportunity (DellaVigna et al., 2012; Andreoni et al. 2017). We propose that such moral costs are stronger when an individual rejects a certain donation, compared to an uncertain one (Exley, 2015). Individuals who prefer the private payment to the donation hence suffer moral costs from rejecting the latter and are willing to pay in order to leave the envelope closed and remain ignorant. By contrast, individuals who prefer the donation to the private payment pay in order to open the envelope and thus acquire information. Therefore, an individual's valuation of the donation

\footnotetext{
3 "Charities have brought skepticism on themselves in some cases by spending large percentages of donated funds on administrative costs and executive salaries. But this complaint is so commonly expressed now that it's starting to sound like a dodge for not giving rather than a principled response to bad management at charities." (Source: The Globe and Mail.com, December 5, 2017).

${ }^{4}$ Related to these findings, Niehaus (2014) develops a model to explain why individuals may choose to avoid learning about the impact of their donations.
} 
opportunity is a central determinant of the price elasticity of moral ignorance.

We find that demand for morally neutral information is significantly stronger than for morally relevant information. In line with our model, individuals who prefer the selfish option to the donation decide to stay morally ignorant if the cost of information is zero. About half of these individuals forego large monetary amounts to stay ignorant, while the other half prefers ignorance only if it is costless. Thus, moral costs of rejecting the donation vary across subjects. Moreover, and also consistent with the model, individuals who prefer the donation to the selfish option exhibit significant willingness to pay for information. Yet again, we see substantial heterogeneity. While some subjects are willing to give up significant amounts of money to acquire information, others only prefer information if it is costless. Overall, moving from small monetary costs to small monetary incentives for information reduces moral ignorance by more than 50 percent. We thus observe a pronounced kink around zero costs of information. This kink is significantly less pronounced in the morally neutral treatments.

Existing research on social norms in economics and psychology has shown that information on norms can often increase prosocial behavior (e.g., Cialdini and Goldstein, 2004; Schultz et al., 2007; Frey and Meier, 2004; Shang and Croson, 2009; Bicchieri and Xiao, 2009). Therefore, in a second study, we investigate whether social norm information is a powerful moral "nudge" to curb moral ignorance. We first elicit social, injunctive norms regarding information demand in the morally relevant envelope game (following Krupka and Weber, 2013). Avoiding information about the donation opportunity and acting selfishly is widely considered morally inappropriate, while obtaining information is widely considered morally appropriate. Remarkably, these norms are rather inelastic to monetary incentives for seeking or avoiding information. The exception is the presence of a kink in norms regarding information demand when information becomes costly, which is in line with the kink in information demand we document in our first experiment.

Through the lens of our model, social norm information could increase individuals' willingness to donate and thereby raise information demand. Indeed, the data show that subjects' valuations of the donation increase from norm provision. However, the demand curve for information does not shift in response to social norms. We observe that information demand only increases directionally when individuals need to pay for information, consistent with positive effects on comparatively altruistic subjects. By contrast, there is a directional decrease when subjects need to pay to 
avoid information. The latter suggests that moral costs of rejecting the donation increase as well, thereby making information less appealing for selfish subjects.

Thus far, little is known about the external validity of experiments measuring information avoidance in moral dilemmas. To address this question, we designed an additional experiment that elicited demand for information regarding animal welfare. ${ }^{5}$ Though consumers often buy products from industrial livestock production, few agree with the living conditions of the animals involved (te Velde et al., 2002; ASPCA 2016; BMEL 2016) and often avoid information about it (Onwezen and van der Weele, 2016). Approximately a week after our experiments, we invited individuals to participate in an unrelated study. In this experiment, we rewarded individuals for correctly answering questions regarding industrial livestock production and offered the opportunity to watch an informative video beforehand. The results indicate that the external validity of the envelope game is high. Individuals who avoid morally relevant information in the envelope game are significantly more likely to avoid information about the conditions of animals involved in intensive farming.

Information avoidance has been widely studied within the moral wiggle room paradigm, in which an individual is unsure whether choosing the option yielding a higher monetary payment for herself hurts or helps another individual. Dana et al. (2007) were the first to show that individuals avoid costless information about the consequences of their choices, and are more likely to act selfishly when doing so (see also, Larson and Capra, 2009; Matthey and Regner, 2011; Feiler, 2014). Ignorance persists when it costs 0.1 Euro (Grossman and van der Weele, 2017) but drops substantially when it costs $\$ 1$ (Cain and Dana, 2012). In contrast to our envelope game, ignorance is considered morally appropriate, which is why norm information is an unlikely mean to reduce ignorance in that context (Krupka and Weber, 2013).

We provide four new, main contributions. First, we measure the price elasticity of information demand, with a broad range of prices making ignorance highly costly up to highly incentivized. We thus measure individual-level willingness to obtain and avoid information depending on monetary costs and benefits. Second, we benchmark preferences to avoid morally relevant information with demand for morally neutral information. Thereby, we identify how much information avoidance is caused by the moral dimension of decision-making, above and beyond other reasons for why individuals may prefer to stay ignorant. Third, we study information avoidance in a charitable giving setting, in which choosing the selfish option implies

\footnotetext{
${ }^{5}$ We follow Bandura (2016) in that avoiding unnecessary harm to humans, animals, and/or nature is of moral relevance.
} 
that no (considerably larger) donation is made. In this setting, ignorance is widely assessed as morally inappropriate, and hence injunctive social norm information can be evaluated as a meaningful tool to decrease ignorance. Fourth, we show that preferences for information avoidance as measured in experimental tasks such as the envelope game are predictive of information avoidance in other morally relevant settings. Overall, we provide novel evidence on the elasticity of (moral) ignorance and its prevalence across different moral contexts.

The remainder of the paper is organized as follows. We next describe the setting in which information demand is studied and provide a brief theoretical background. Section 3 describes the design of the two main experiments and the additional experiment to measure external validity. Section 4 provides the results of the experiments and Section 5 discusses their external validity. Section 6 concludes.

\section{Avoiding Morally Relevant Information}

\subsection{The Envelope Game}

We study information avoidance in the following game. An individual is assigned an envelope that contains a $\$ 10$ donation to the Malaria Consortium, a non-profit organization fighting Malaria in sub-Saharan Africa, with $p=0.5$. Otherwise (thus also with $p=0.5$ ), the envelope is empty. The individual makes two decisions. First, she chooses whether or not to open the envelope. If she does not open the envelope, she chooses between receiving $\$ 2.5$ for herself and the uncertain envelope. If she opens the envelope, she first learns whether the envelope contains the $\$ 10$ donation or is empty. Then, she chooses between the envelope and receiving $\$ 2.5$ for herself.

\subsection{Theoretical Background}

In the following, we solve the envelope game. We start with the case when opening or leaving the envelope closed is costless, then we turn to the case with payments for opening the envelope or payments for keeping it closed. We also provide predictions on how norm provision may influence the decision to open the envelope. We refer to choosing to take the private payment instead of the envelope as choosing the "selfish option", and choosing the envelope as "donating."

We assume that utility takes the form of $u(x)=x^{r}$ with risk parameter $r>0$. As we will see, the predictions will be independent of the risk parameter. Yet they hinge 
on how much the agent values the donation of 10, i.e., on her monetary equivalent, which we denote by $\alpha \cdot 10$. Information demand also depends on whether there is a moral cost associated with rejecting the certain donation of 10 or not. The standard economic approach would be to assume that this cost is zero. Then, leaving the envelope closed never dominates. However, existing theoretical and experimental work has shown that rejecting a certain donation can induce guilt (e.g., DellaVigna et al., 2012, Andreoni et al., 2017). We model this moral cost as a discount factor $\beta$ of the 2.5 payment that individuals can take for themselves. An individual who rejects the certain donation gets $\beta \cdot 2.5$ with $\beta<1$. In this model, $\beta$ represents the additional cost of rejecting a donation when it is certain, relative to when it is uncertain. As we show, this cost can make it dominant for individuals to pay to keep uncertainty about the donation.

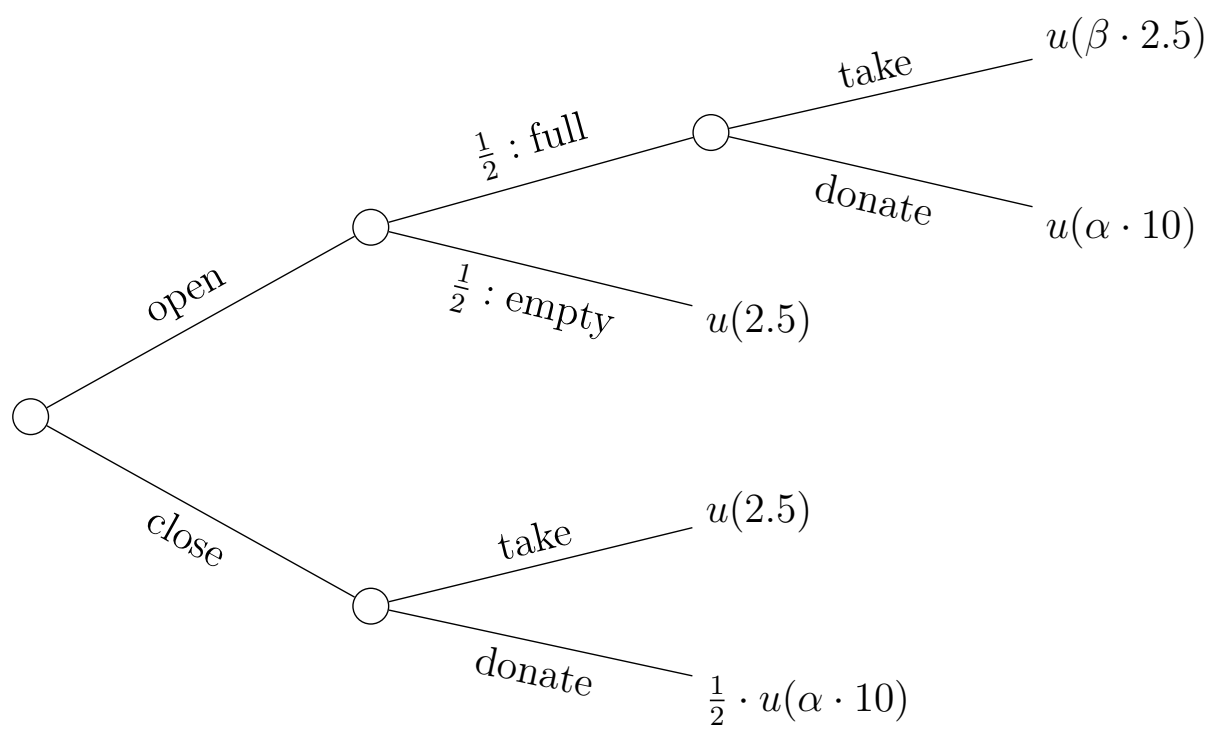

Figure 1: Game tree of the envelope game, when information is costless

We solve the game by backwards induction, using the game tree as depicted in Figure 1. We begin with the decision to take or donate after an initial decision to open. In this case, it is strictly optimal to take the selfish amount if $u(\beta \cdot 2.5)>$ $u(\alpha \cdot 10)$. This is equivalent to $\alpha<\beta \cdot \frac{1}{4}$, due to the monotonicity of $u$. At the other endnode, after an initial decision not to open, it is optimal to take the selfish monetary amount if $u(2.5)>\frac{1}{2} \cdot u(\alpha \cdot 10)$. By our assumption that $u(x)=x^{r}, r>0$, this is equivalent to $\alpha<2^{\frac{1}{r}} \cdot \frac{1}{4}$. We can thus turn to the initial decision to open the 
envelope and its dependence on $\alpha$. The utility from opening is ${ }^{6}$

$$
\frac{1}{2} u(2.5)+\frac{1}{2} u(\beta \cdot 2.5) \quad \text { if } \alpha<\beta \cdot \frac{1}{4}
$$

and

$$
\frac{1}{2} u(2.5)+\frac{1}{2} u(\alpha \cdot 10) \quad \text { if } \alpha \geq \beta \cdot \frac{1}{4} .
$$

The utility from not opening is

$$
u(2.5) \quad \text { if } \alpha<2^{\frac{1}{r}} \cdot \frac{1}{4}
$$

and

$$
\frac{1}{2} u(\alpha \cdot 10) \quad \text { if } \alpha \geq 2^{\frac{1}{r}} \cdot \frac{1}{4}
$$

As $\beta<1<2^{\frac{1}{r}}$, we thus distinguish three cases depending on the location of $\alpha$. If $\alpha$ lies below both thresholds, $\alpha<\frac{\beta}{4}$, donating is suboptimal regardless of the decision in the first stage. In this case, the comparison

$$
\frac{1}{2} \cdot u(2.5)+\frac{1}{2} u(\beta \cdot 2.5)<u(2.5)
$$

implies that leaving the envelope closed is optimal. ${ }^{7}$ In the intermediate case when $\beta \cdot \frac{1}{4} \leq \alpha<2^{\frac{1}{r}} \cdot \frac{1}{4}$, we have to compare the utility of $\frac{1}{2} \cdot u(2.5)+\frac{1}{2} \cdot u(\alpha \cdot 10)$ from opening and $u(2.5)$ from leaving the envelope closed. Opening is thus optimal for $\alpha \geq \frac{1}{4}$. In the third case $\alpha \geq 2^{\frac{1}{r}} \cdot \frac{1}{4}$, the relevant comparison is between $\frac{1}{2} \cdot u(2.5)+\frac{1}{2} \cdot u(\alpha \cdot 10)$ and $\frac{1}{2} \cdot u(\alpha \cdot 10)$. In this case, opening the envelope is optimal.

In sum, opening the envelope is optimal for $\alpha \geq \frac{1}{4}$ while keeping it closed is optimal for $\alpha<\frac{1}{4}$. Hence, we obtain that an agent with a monetary equivalent for the donation that is not too high prefers to leave the envelope closed.

Let us now consider the case where there are monetary incentives $m_{o}$ in case the agent opens and $m_{c}$ in case the agent keeps the envelope closed, as shown in the game tree in Figure 2. For simplicity, we focus on the case $r=1 .^{8}$ The behavior

\footnotetext{
${ }^{6}$ Here and in the following, we assume that an agent who is indifferent between taking the money and donating will donate. Similarly, the agent favors options with a higher donation probability in case of indifference.

${ }^{7}$ In the boundary case $\beta=1$, the agent is instead indifferent between opening and not opening.

${ }^{8}$ In the appendix, we also address cases of risk aversion and of risk lovingness.
} 
at the endnodes is not affected by the additional costs of opening or leaving the envelope closed. After opening and finding a full envelope, the agent donates if $\alpha \geq \frac{\beta}{4}$. If the envelope is closed, the agent donates if $\alpha \leq \frac{1}{2}$.

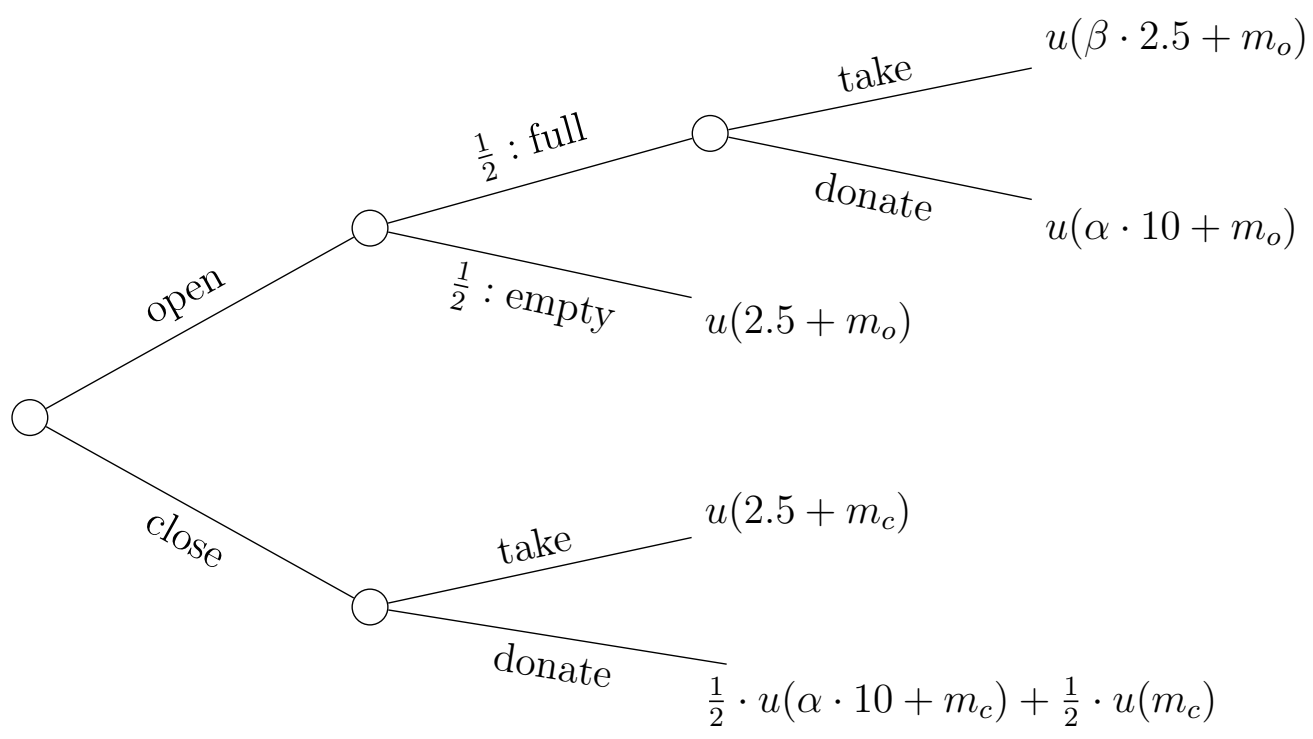

Figure 2: Game tree of the envelope game, when information acquisition or avoidance is monetarily incentivized

For the initial opening decision, we distinguish again three cases, depending on whether $\alpha<\frac{\beta}{4}, \alpha \in\left[\frac{\beta}{4}, \frac{1}{2}\right)$, or $\alpha \geq \frac{1}{2}$. First, for $\alpha<\frac{\beta}{4}$, the relevant comparison is now between a utility of $\frac{1+\beta}{2} 2.5+m_{o}$ from opening and $2.5+m_{c}$ from keeping it closed. Opening is strictly dominant if the difference between $m_{o}$ and $m_{c}$ is positive and sufficiently large,

$$
m_{o}-m_{c}>5\left(\frac{1}{4}-\frac{\beta}{4}\right)
$$

Second, for $\alpha \in\left[\frac{\beta}{4}, \frac{1}{2}\right)$, the comparison is between a utility of $\frac{2.5+\alpha \cdot 10}{2}+m_{o}$ from opening and $2.5+m_{c}$ from keeping the envelope closed. Opening strictly dominates if

$$
m_{o}-m_{c}>5\left(\frac{1}{4}-\alpha\right)
$$

Otherwise, it is best to leave the envelope closed. Observe that the right hand side of (2) switches signs at $\alpha=\frac{1}{4}$. Thus, if $\alpha<\frac{1}{4}$, a positive value of $m_{o}-m_{c}$ is needed to motivate the agent to open the envelope. In contrast, for $\alpha>\frac{1}{4}$, the agent will still open the envelope in case where $m_{c}$ is slightly larger than $m_{o}$.

In the third case $\alpha \geq \frac{1}{2}$, i.e., for subjects with a very high valuation for the donation, we have to compare $\frac{2.5+\alpha \cdot 10}{2}+m_{o}$ from opening and $\frac{\alpha \cdot 10}{2}+m_{c}$ from keeping 
the envelope closed. Opening strictly dominates if

$$
m_{o}-m_{c}>-\frac{5}{4}
$$

i.e., unless $m_{c}$ is quite high it is best to open the envelope.

To summarize the three cases, if $m_{o}-m_{c} \leq-\frac{5}{4}$, it is optimal to keep the envelope closed regardless of $\alpha$. If $m_{o}-m_{c}>5\left(\frac{1}{4}-\frac{\beta}{4}\right)$, it is optimal to open the envelope regardless of $\alpha$. In the intermediate case

$$
-\frac{5}{4}<m_{o}-m_{c} \leq 5\left(\frac{1}{4}-\frac{\beta}{4}\right)
$$

there exists a threshold value of $\alpha_{t} \in\left(\frac{\beta}{4}, \frac{1}{2}\right)$ such that opening is optimal for $\alpha \geq \alpha_{t}$ while keeping the envelope closed is optimal for $\alpha<\alpha_{t}$. The value of $\alpha_{t}$ is given explicitly through

$$
\alpha_{t}=\frac{1}{4}-\frac{m_{o}}{5}+\frac{m_{c}}{5} .
$$

In the experiments, $m_{o}-m_{c}$ ranges from $-\$ 2$ to $\$ 2$. Figure 3 depicts optimal information demand and donation behavior depending on monetary incentives and levels of altruism, $\alpha$, for three cases of moral costs. As we see, in most cases, it is the level of altruism $\alpha$, that determines whether individuals open the envelope or leave it closed (see the transition from the green to the yellow area). If moral discounting via $\beta$ is small, selfish individuals may open the envelope and bear the moral costs when taking the selfish option if monetary incentives for opening are pronounced (blue area). Moreover, if monetary incentives to leave the envelope closed are sizable, altruistists may leave the envelope closed and donate the closed envelope (red area).

In addition to the impact of monetary incentives, we study empirically the causal effects of providing information about moral norms. We investigate two types of norms in the envelope game. We either inform agents that getting information is considered morally appropriate by a vast majority of agents, or we inform them that leaving the envelope closed and getting the selfish monetary amount is considered morally inappropriate. In terms of our model, this could lead to an increase in the monetary equivalent of the donation, i.e., to an increase in $\alpha$. Such an increase could lead to more demand for information in the envelope game (unless $\alpha$ becomes very large), and thereby, curb moral ignorance. However, there may be a partly opposing effect. The moral costs of rejecting a certain donation could increase from 

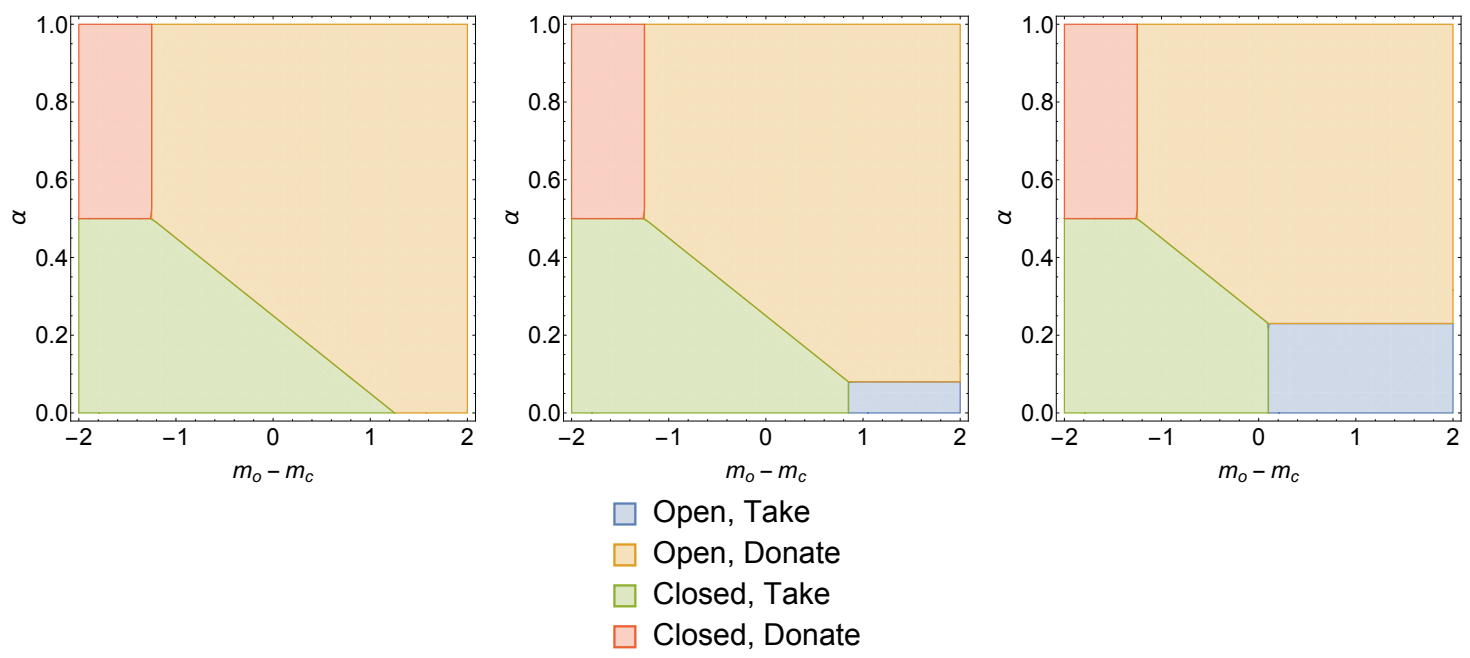

Figure 3: Optimal decisions for a risk neutral individual with $\beta=0.36,0.66,0.96$, respectively

norm provision, i.e., the moral discounting via $\beta$ could become more intense. A decrease in $\beta$ would reduce the demand for information when incentives to obtain information are positive. In contrast, it would have no impact when individuals pay to open the envelope $\left(m_{o}=0\right.$ and $\left.m_{c}>0\right)$. Therefore, all in all, we expected that norm provision would have a positive impact on information seeking.

\section{Experimental Design}

In the following, we present the designs of two experiments that examine the impact of incentives (Experiment 1) and social norms (Experiment 2) on information avoidance. In total, we analyze the decisions of 1304 participants. The design of the two experiments is summarized in Table 1 . The experiments were pre-registered. ${ }^{9}$

\subsection{Experiment 1}

In this experiment we study the effect of incentives on preferences for information in the envelope game. In the main treatment, which we refer to as the Donation treatment, the envelope contained a $\$ 10$ donation with a $50 \%$ chance. We varied the payment for opening the envelope, from $-\$ 2$ to $\$ 2$. Specifically, individuals made nine independent decisions, with the following range of payments for opening the

\footnotetext{
${ }^{9}$ Pre-registration was done on aspredicted.org.
} 
envelope: $\$ 2, \$ 1, \$ 0.50, \$ 0.10, \$ 0,-\$ 0.10,-\$ 0.50,-\$ 1$ and $-\$ 2 .{ }^{10}$

The main hypothesis in this experiment was that individuals would strongly prefer und thus pay for information avoidance. As we discussed theoretically above, information avoidance is attractive if subjects prefer taking $\$ 2.50$ over making a $\$ 10$ donation. We expected this to be the case for most subjects. However, if subjects value the $\$ 10$ donation more over taking $\$ 2.50$, they should prefer to open the envelope.

To benchmark preferences to avoid morally relevant information against preferences to avoid (or seek) information in a morally neutral decision, we ran two control treatments (Self treatments). In these, the uncertain donation was replaced by an uncertain payment for subjects themselves.

Thus, in the Self treatments, the set-up was similar to the Donation treatment, with the only difference that the envelope contained money for the individual instead of a donation. The envelope contained nothing or a payment for the individual $(\$ 5$ in the Self-5 treatment, $\$ 10$ in the Self-10 treatment). Again, the likelihood that the envelope contained money was $p=0.5$. As in the Donation treatment, individuals chose between the envelope and a $\$ 2.50$ payment. They could open the envelope beforehand, with the same range of prices for opening as in the Donation treatment. In these treatments, there is no moral reason for subjects to pay money in order to leave the envelope closed. ${ }^{11}$

\section{$3.2 \quad$ Experiment 2}

In Experiment 2, run two months after Experiment 1, we study norms regarding information avoidance. A large number of studies have shown that social norms affect individuals' behavior in an array of contexts (e.g., Cialdini and Goldstein, 2004; Schultz et al., 2007). In the context of donation behavior, descriptive norm information, which informs about others' behavior, increases charitable giving (McAuliffe et al. 2017, Shang and Croson 2009; Martin and Randal, 2008). Injunctive norm information, which describes how individuals should behave, can also increase prosocial

\footnotetext{
${ }^{10}$ Individuals knew that whether the envelope contained the donation or not independently varied across all nine decisions. To simplify elicitation, decisions were made one at a time, on separate screens, and the order of the questions always followed the same descending pattern of payments for opening the envelope. The instructions are presented in Appendix A.

${ }^{11}$ Standard theory would predict that subjects open the envelope unless opening becomes sufficiently costly. Yet, some individuals may nevertheless prefer to leave the envelope closed if they have a preference to maintain uncertainty, as has been found in financial decision-making (e.g. Karlsson et al., 2009).
} 
Table 1: Experimental Design

\begin{tabular}{cll}
\hline Experiment & Treatments & Description \\
\hline 1 & Donation & Donation uncertainty: $\$ 10$ donation with $p=0.5, \$ 0$ otherwise \\
& Self-5 & Payment uncertainty: $\$ 5$ payment with $p=0.5, \$ 0$ otherwise \\
& Self-10 & Payment uncertainty: $\$ 10$ payment with $p=0.5, \$ 0$ otherwise \\
\hline 2 & Norms & Elicitation of social norms regarding information demand \\
& NoNorm & Donation treatment without norm information \\
& Norm-Avoid & Donation treatment, informing avoidance is morally inappropriate \\
& Norm-Seek & Donation treatment, seeking information is morally appropriate \\
\hline
\end{tabular}

behavior (e.g., Bicchieri and Xiao, 2009; Hallsworth et al., 2017).

In our context, given the widespread avoidance of information in Experiment 1, informing other subjects about this behavior using descriptive social norms would unlikely curb ignorance. Thus, there is little scope for providing (truthful) descriptive information as a means to decrease ignorance. By contrast, if most individuals evaluate ignorance as morally inappropriate, injunctive norm provision could potentially increase information demand.

Little is known about the perceived morality of information avoidance, and whether providing information about its moral inappropriateness can reduce it. Philosophers have proposed the "Ignorance Thesis", which states that, if an individual chooses to remain ignorant in a moral decision, she is culpable for acts that derive from it (Zimmerman, 1997; Rosen, 2003; Guerrero, 2007). If individuals broadly agree with this view, we should find injunctive norms in favor of informational demand.

Yet, Krupka and Weber (2013) elicit norms in the standard moral wiggle room game in Dana et al. (2007), and find that information avoidance is considered morally appropriate. We expected that in our context, a majority of subjects would consider information avoidance morally inappropriate, because the only way to remove the moral relevance of the decision is to open the envelope and find that it is empty. Reassuringly, this is what we find.

We first ran a treatment to elicit the perceived morality of information avoidance and donation decisions. Using the method proposed by Krupka and Weber (2013), we elicited the moral appropriateness of decisions in the Donation treatment in Experiment 1. Subjects rated the options on a four-point Likert scale. The four categories were "very morally appropriate", "somewhat morally appropriate", "somewhat morally inappropriate", and "very morally inappropriate". Subjects' 
ratings were elicited for each of the nine information decisions, i.e., for each cost of information (avoidance). As in Krupka and Weber (2013), subjects were incentivized to correctly estimate the rating that most subjects would provide. They earned $\$ 5$ if their rating in a randomly drawn decision coincided with the favorite answer of the other participants in that treatment, and zero otherwise.

After eliciting injunctive norms, we provided them to other subjects. Specifically, we randomly allocated a new set of participants to one of three treatments. The first treatment was a NoNorm treatment, which was the same as the Donation treatment in Study 1. The second was a Norm-Avoid treatment, in which individuals were informed that over $70 \%$ of individuals considered it morally inappropriate to take the $\$ 2.50$ payment, without seeking information about the envelope's content first. The third treatment was a Norm-Seek treatment, in which individuals were told that over $70 \%$ of individuals considered seeking information, by opening the envelope first, morally appropriate. ${ }^{12}$ For robustness, we tested both positively and negatively framed norm information. Each message was shown once, just before individuals started making their information decisions. As we will show, ratings of moral appropriateness did not vary strongly with the cost of avoidance, which allowed us to provide a single general message before individuals made decisions.

Our main hypotheses were that providing information about the moral inappropriateness of avoiding information and choosing not to donate (Norm-Avoid), or the moral appropriateness of information seeking (Norm-Seek) would decrease information avoidance compared to the NoNorm treatment, respectively. We also hypothesized that subject's valuations for the donation would increase from norm provision. In fact, this is the mechanism in our model for why subjects should display more interest in getting information in the Norms treatments. ${ }^{13}$

\subsection{Follow-Up: External Validity of Information Preferences}

An important question when measuring information avoidance in an experimental task is whether such behavior is externally valid in another incentivized, different setting. For example, recent work has shown that individuals avoid morally relevant

\footnotetext{
${ }^{12}$ The exact message shown to participants was "over $70 \%$ of MTurkers who evaluated the actions in this part of the study consider it morally inappropriate (appropriate) to choose the option "Get $\$ 2.5$ " without revealing what the envelope contains first ("Reveal what the envelope contains" first)."

${ }^{13}$ As pointed out in the theoretical framework section, there may be a (partly) opposing effect if norm provision also increases the moral costs of rejecting a certain donation. Yet as the analysis shows, this could only foster a desire for ignorance if obtaining information is costly.
} 
information about the refugee crisis in Swedish media (Freddi, 2017). There is, however, no evidence to our knowledge about the predictive validity of experimental measures of information avoidance in a different, real setting. To test the predictive power of the elicited informational preferences, we measured information avoidance in an unrelated, later morally relevant task.

We invited participants of our studies to an unrelated work task between 7 and 10 days after they had participated in the experiments described above. The task consisted in answering questions about the living conditions of cows and their calves in conventional dairy production. We chose this topic because the willingness to improve living conditions of farm animals correlates with a higher moral and prosocial inclination (Albrecht et al., 2017). Even though many consumers buy products from intense animal farming, many state that they do not agree with the living conditions of animals involved (te Velde et al., 2002). Therefore, if individuals want to continue their consumption of conventional dairy products, they may have an incentive to avoid information about cows' living conditions.

Participants earned a $\$ 0.15$ bonus if they answered two questions about the treatment of cows and their calves in conventional farming correctly. Before proceeding to the questions, they were offered the option to watch a 1-minute informational video. We study how frequently individuals choose to watch the video as a measure of information avoidance in another morally relevant and incentivized setting. The main question is whether individuals who choose to avoid information in the envelope game also avoid watching the video.

\subsection{Experimental Procedures}

\subsubsection{Other Determinants of Information Avoidance}

In all experiments, subject first played the envelope game. Thereafter, we elicited several control measures of individuals' preferences.

As we saw in the Theoretical Background section, a subject's valuation of the donation $(\alpha)$ is particularly relevant for her decision whether or not to avoid information. To measure this valuation, subjects participated in two tasks that elicited their preferences for the opened as well as for the closed envelope. First, we elicited the monetary equivalent of a certain $\$ 10$ donation, by asking the individual to make eight binary choices between the donation and payments to her that increased from $\$ 0.10$ to $\$ 10$. Second, we elicited the monetary equivalent of a $\$ 10$ donation that 
occurs with a $50 \%$ chance. In this task, individuals made again eight binary choices, each between the potential donation and a payment that increased from $\$ 0.01$ to $\$ 5 .^{14}$ For each individual, we calculate her monetary equivalent of a certain (uncertain) donation as the maximum value of the payment to her that she was willing to give up instead of the donation.

At the end, in a questionnaire, we elicited preferences for information (avoidance) according to the Monitors-Blunters Scale (Miller, 1987), moral preferences according the Machiavellianism scale (Christie and Geis, 1970), as well as gender, age, education and frequency of work in Mturk.

Existing research in psychology has developed scales to measure preferences for information avoidance and attachment to social norms. The Monitors-Blunters Scale (Miller, 1987) is a well-established scale that measures information-seeking behaviors under threat. Individuals who prefer information before a stressful event are considered monitors, while those who avoid information are considered blunters. A higher score on the scale implies more monitoring. We test whether subjects who express more desire for information in the Monitors-Blunters Scale less likely avoid information in the Donation treatment.

The Machiavellianism Score measures whether an individual considers herself as attached or detached from moral and social norms (Christie and Geis, 1970). A subject classified as more machiavellian according to the Machiavellianism Scale may feel lower moral costs from rejecting a donation. Therefore, we test whether individuals classified as more machiavellian have a lower willingness to avoid information in the Donation treatment compared to other subjects.

In the Self treatments we also elicited a control measure of subjects' risk preference. After subjects had completed the envelope game, we elicited their risk preferences and used the same questionnaires described above. Since in this treatment there was no mention of a donation opportunity, we did not measure subjects' valuation of the $\$ 10$ donation to fight malaria. We provide detailed information on these measures and descriptive statistics in Appendix B.

\subsubsection{Sample}

There were 593 subjects in Experiment 1, dropping inconsistent subjects as preregistered. Of these, 294 participated in the main treatment, the Donation treat-

\footnotetext{
${ }^{14}$ Subjects knew that the computer either drew one of these two tasks or the main part of the experiment for payment, and that exactly one of the decisions taken in these would accordingly become implemented.
} 
ment, 147 in Self-5 and 152 in Self-10. In Experiment 2, we first conducted the Norms treatment, with 102 participants. We thereafter conducted the treatments NoNorm, Norm-Avoid and Norm-Seek at the same time and randomly assigned subjects to one of these three treatments. There are 200, 201 and 208 subjects in each treatment, respectively. These sample sizes were chosen to be able to detect a $\$ 0.15$ change in willingness to pay for information in the presence of social norm information (with an $80 \%$ power). Throughout, we exclude individuals who answered inconsistently as pre-registered.

Since Experiment 2 was conducted two months after Experiment 1, we again elicited the behavior of individuals in the Donation treatment, labeled NoNorm treatment here, to control for any differences in the sample. ${ }^{15}$ We find that, in contrast to Experiment 1, the share of female participants in Experiment 2 was significantly higher, $53.0 \%$, compared to $45.2 \%$ in Experiment 1 ( $t$-test, $p$-value $<0.01) .{ }^{16}$ In line with previous literature on gender effects in altruistic behavior (e.g., Andreoni and Vesterlund, 2001), we observe a higher monetary equivalent of the certain $\$ 10$ donation in this experiment, $\$ 2.9$, compared to Experiment $1, \$ 1.9$ ( $t$-test, $p$-value $<0.01)$. We also observe a weaker preference to avoid information in the NoNorm treatment than in the Donation treatment in Experiment 1 ( $t$-test, $p$ value $<0.01$ ), consistent with our prediction (and finding) that a higher willingness to donate is associated with a lower willingness to pay for information avoidance. The analysis of Experiment 2 hence focuses on the treatment effect of providing information about social norms within this experiment.

On average, $86.3 \%$ of participants in the experiments completed the follow-up task in which we measure information avoidance about cows' living conditions, to externally validate the morally relevant envelope game. ${ }^{17}$ Since the relationship between information avoidance in the envelope game and the follow-up task is qualitatively similar in the Donation treatment in Experiment 1 and in Experiment 2, we focus our analysis on Experiment 2, where we can also examine whether social

\footnotetext{
${ }^{15}$ We conducted a first smaller version of Experiment 2 that suggested that results would be incomparable to the former Donation treatment run two months earlier. We hence conducted a larger study thereafter, and focus on this data. Including the smaller study does not change the conclusions.

${ }^{16}$ Age, educational attainment and MTurk experience of participants did not differ $(t$-tests, $\mathrm{p}$ value $>0.05)$.

${ }^{17}$ The return rate is $83.7 \%$ in the Donation treatment in Experiment 1, 91\% in the Donation (-NoNorm) in Experiment 2, and $87.6 \%$ and $84 \%$ in the Norm-Avoid and Norm-Seek treatments, respectively. Within Experiment 2, the difference in return rates between the Norm-Seek and NoNorm treatments is significant $(p$-value $=0.036)$.
} 
norms information had a long-run effect on information avoidance.

\section{Results}

\subsection{Experiment 1: Information Avoidance and Incentives}

Figure 4 displays the share of individuals who demand information, that is, open the envelope, for each price of information, by treatment. The bottom black line depicts information demand in the Donation treatment. We observe that $31 \%$ of individuals demand information when the cost of information is zero. This implies that the majority, i.e., $69 \%$ of individuals, avoid information when it is costless. Among these information avoiders, $65 \%$ are willing to pay at least 10 cents, and $57 \%$ are willing to pay more than 50 cents for moral ignorance. Further, $44 \%$ of them are willing to pay at least $\$ 1$, and $22 \%$ are willing to pay $\$ 2$ for ignorance. This illustrates that, on one hand, a small monetary cost reduces moral ignorance significantly, by 35 percent. On the other hand, for a substantial proportion of subjects, preferences for moral ignorance are strong. On average, across all subjects in the Donation treatment, individuals pay 40 cent in order to stay morally ignorant. This is significantly different from $\$ 0$ ( $t$-test, $p$-value $<0.01)$. This suggests that the moral cost of rejecting the certain donation is substantial.

Individuals who choose to avoid information pick the selfish payment for themselves in a large majority of cases (88.4\%, on average). Individuals who choose to obtain information tend to have a larger interest in giving. The share of individuals who donate when they learn that there is a $\$ 10$ donation in the envelope increases from $49 \%$ to $100 \%$, as the price of information increases. This is consistent with selection. In line with the theoretical framework, subjects with a higher valuation for the donation are more willing to pay for information acquisition, and then opt for the donation if the envelope contains it. ${ }^{18}$

In the Self treatments, in contrast, we observe that individuals are on average willing to pay for information acquisition. The average willingness to pay for information in the Self-10 treatment is $\$ 0.83$, and $\$ 0.29$ in the Self- 5 treatment. In both cases, this is significantly different from zero ( $t$-test, $p<0.01)$. The willingness to obtain information in the Self-10 is higher than in the Self-5 treatment $(p<0.01)$, in line with standard comparative statics of information preferences.

\footnotetext{
${ }^{18}$ Detailed information on the distribution of information choices by price of information, as well as behavior conditional on obtaining information, is provided in Appendix C.
} 


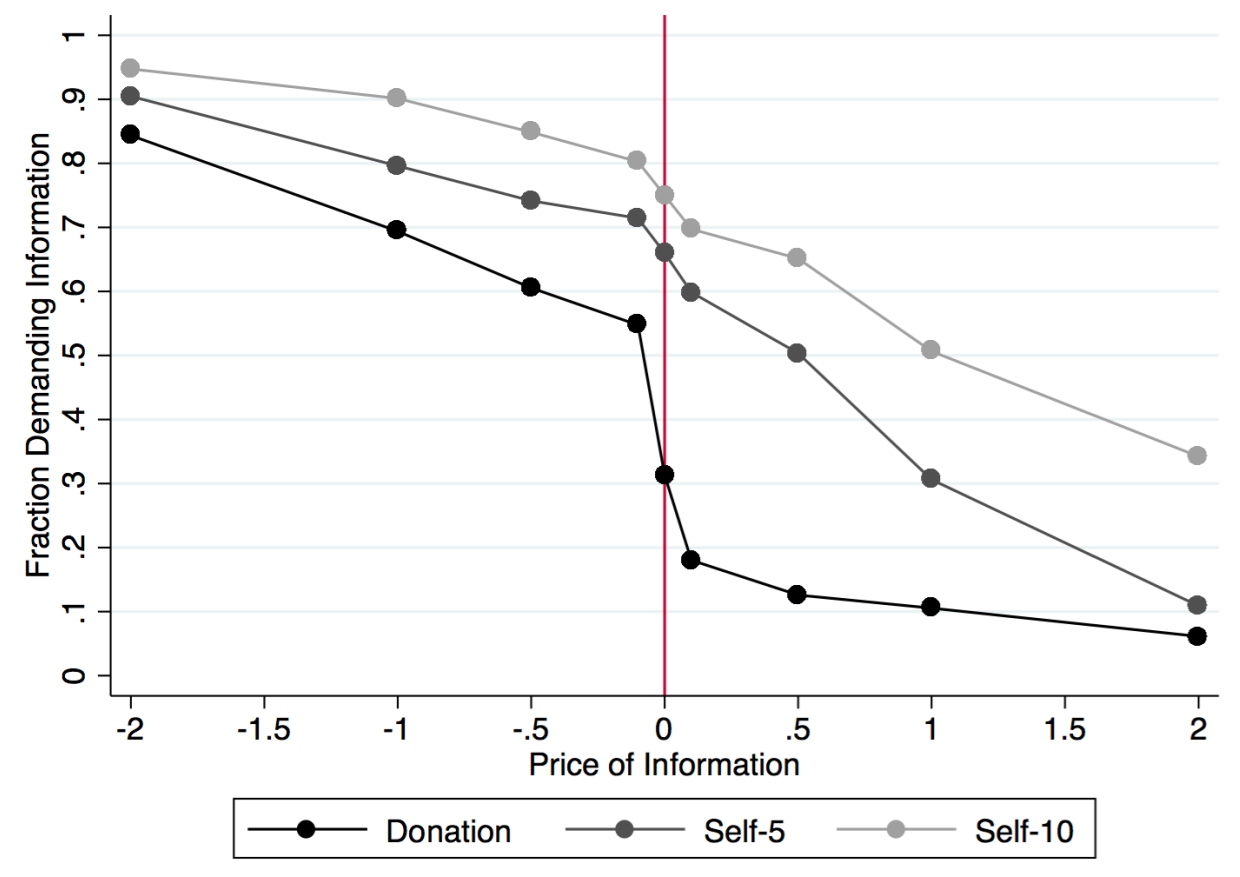

Figure 4: Information Avoidance, by treatment

The Self-5 and Self-10 provide a benchmark for information demand in a morally neutral companion context, relative to the morally relevant context in the Donation treatment. Assuming linearity, we find that willingness to pay to avoid information in the Donation treatment is equivalent to willingness to pay to obtain information when the envelope contains ca. $\$ 6$ for the individual with $50 \%$ chance, i.e., a Self-6 treatment.

Overall, preferences for moral ignorance in the Donation treatment when the cost of information is zero are comparable to those in experiments based on the moral wiggle room paradigm by Dana et al. (2007). Our morally neutral treatments indicate that roughly half of ignorance is specific to the moral relevance of the situation.

The patterns of information demand in the Donation treatment indicate that, not only is there significant information avoidance, but also that the relationship between prices and information demand changes when informational choices are morally relevant. Specifically, in the Donation treatment, we observe a significant kink in the demand curve around $\$ 0$. This kink is consistent with suggestive evidence in Grossman and van der Weele (2017), who find that information demand drops to zero when there is a 0.10 Euro incentive to avoid information, in a session with 10 
subjects in the moral wiggle room paradigm of Dana et al. (2007).

Figure 4 indicates that the kink around $\$ 0$ is more pronounced in the Donation treatment than in the Self treatments. There are also differences in price sensitivity when information is costless and costly, relative to the Self- 5 and $\$ 10$ treatments. We conduct an exploratory analysis of these differences in Table 2. This table presents the results of linear probability models on the decision to demand information, as a function of the price of information. To account for the kink in the demand curve around 0 , the regression includes an indicator variable for costly information, i.e., when prices are strictly positive. To allow for the relationship between price and information demand to vary when information is costly relative to when it is costless, the regression also includes an interaction term between the indicator for costly information and the price of information.

The results shown in columns (1)-(3) of Table 2 display the relationship between price and information demand in the Donation treatment, the Self- 5 and the Self-10, respectively. Column (4) shows that the effect of price is different in the Donation treatment, compared to the Self treatments, in three ways. First, in the Donation treatment, we observe a pronounced kink, of 27 percentage points, around $\$ 0$. This is significantly different from the Self treatments, in which there is more demand for information and a smaller kink of 6 percentage points. Second, when individuals are paid to acquire information, price sensitivity is stronger in the Donation treatment than in the Self treatments. This is explained by the fact that most subjects always demand information in the Self treatments, while some subjects exhibit a preference to avoid information in the Donation treatment. Third, price sensitivity is weaker in the Donation treatment than in the Self treatments when individuals have to pay for information. Since only few subjects have a preference to pay for information in the Donation treatment, it may not be surprising to see a smaller elasticity here.

\subsection{The Determinants of Informational Preferences in the Moral Domain}

To better understand information preferences in the Donation treatment, and in particular the kink around $\$ 0$, we examine the determinants of informational choices in more detail. As highlighted in the theoretical framework, an important predictor of informational preferences in the donation context is the individual's willingness to donate. We use the monetary equivalent of the $\$ 10$ donation elicited in the experiment to examine its relationship with the choice to avoid information. First, 
Table 2: Demand for Information Across Domains

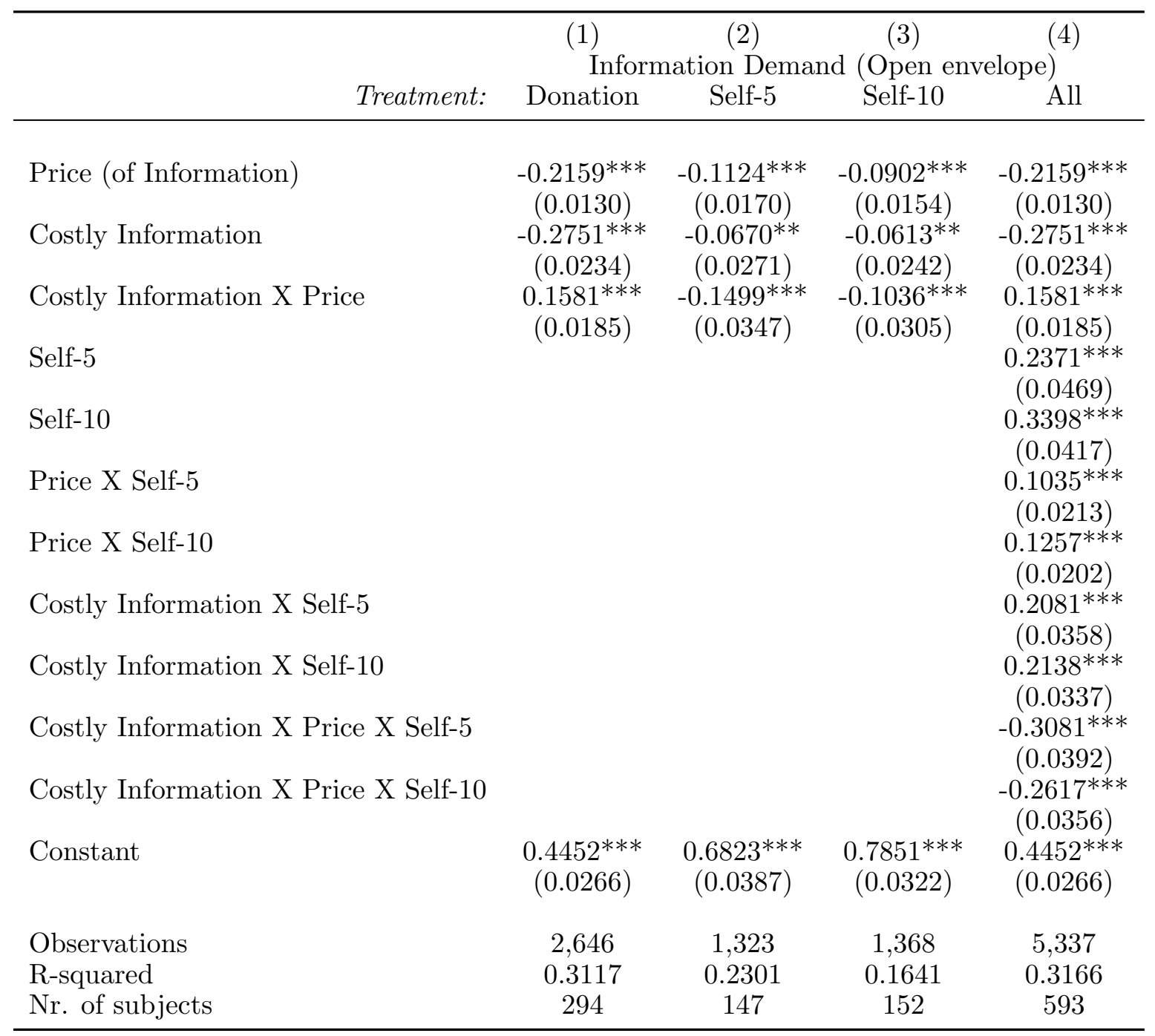

Notes: This table examines the impact of price on information demand in the Donation, Self-10 and Self- 5 treatments. The dependent variable takes value 1 if the individual demands information (opens envelope). Robust clustered standard errors shown in parentheses. ${ }^{* * *} p<0.01$, ** $p<0.05,{ }^{*} p<0.1$

we find that there is a significantly negative relationship between an individual's monetary equivalent of the $\$ 10$ donation (willingness to donate, or WTD) and her willingness to pay for information, as shown in Figure 5a. The Spearman correlation coefficient is -0.39 ( $\mathrm{p}$-value $<0.01$ ). Thus, in line with the model, it is individuals with a low willingness to donate who tend to pay for moral ignorance.

To better understand the kink around $\$ 0$, we first explore whether the kink is driven by a specific subgroup of people within our population, or whether it is a 


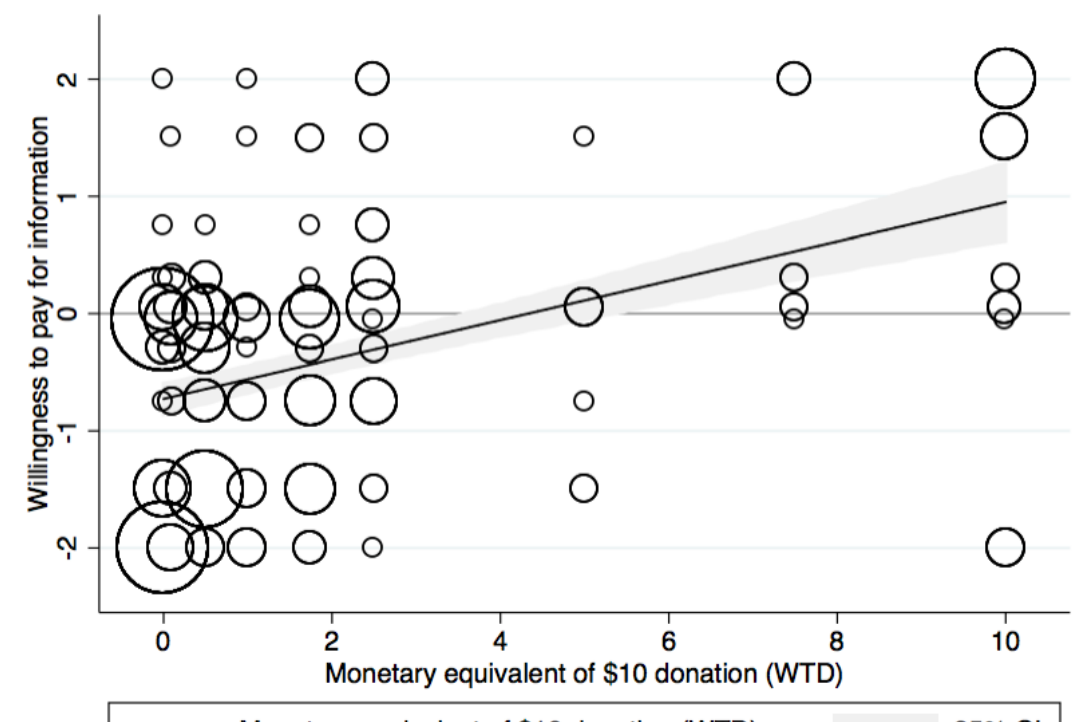

(a) Willingness to Pay for Information and Donation Valuation

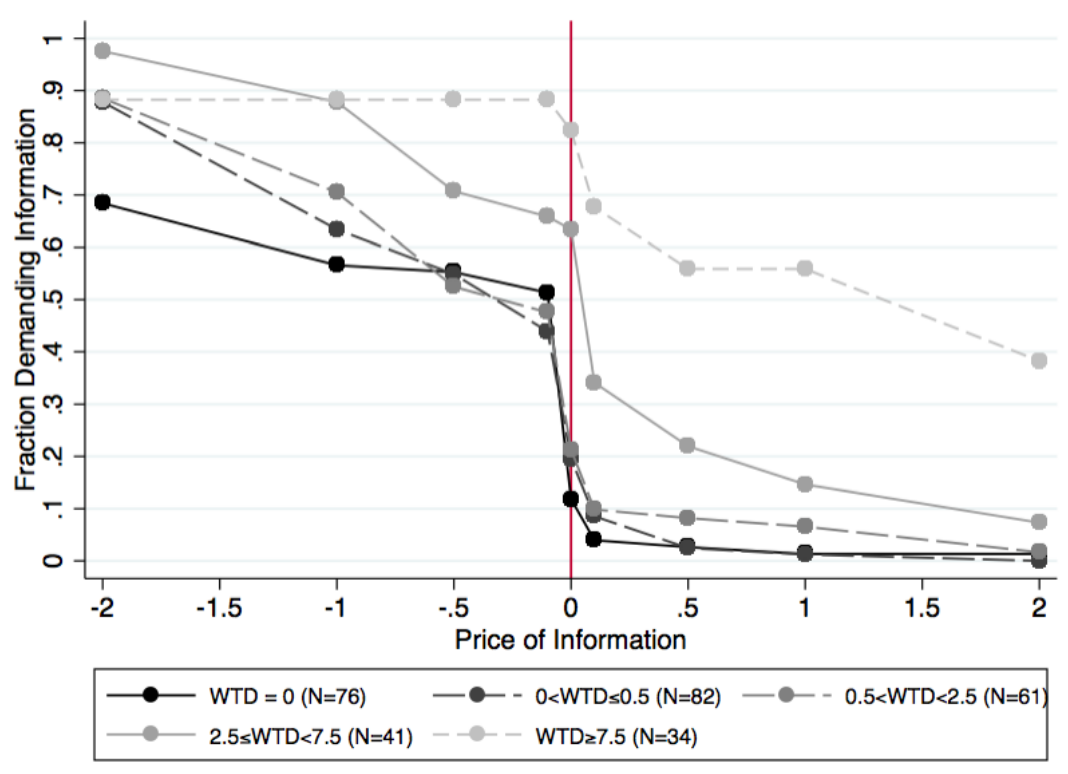

(b) Demand for Information by Donation Valuation

Figure 5: Information Preferences and Donation Preferences

broad phenomenon. We classify our population into five subgroups, depending on their monetary valuation of the donation. Figure $5 \mathrm{~b}$ shows the information demand curve for each subgroup. The darker curves indicate lower monetary valuations for the donation, while the lighter curves indicate higher valuations. A kink of at least 20 percentage points around $\$ 0$ is observed for all subgroups. 
Why is the kink around $\$ 0$ observed? In line with the theoretical framework, subjects who value the $\$ 10$ donation less than the selfish option (WTD $<2.5)$, exhibit a kink to the left of $\$ 0$. If the price of information is $\$ 0$ or higher, these individuals predominantly choose not to obtain information. This kink before $\$ 0$ suggests that, a seizable share of individuals has a small moral cost of rejecting the certain donation. They only avoid information when avoidance is costless. In terms of the model, their $\beta$ is slightly below 1 . At the same time, as the price of information increases from $-\$ 2$ to $-\$ 0.10$, information demand decreases, revealing that there is a significant fraction of individuals who avoids information at a larger cost, suggestive of heterogeneity in $\beta$.

Individuals who value the $\$ 10$ donation more than the selfish option (WTD $\geq 2.5$ ) exhibit a kink to the right of $\$ 0$. On average, $72 \%$ of individuals with $W T D \geq 2.5$ obtain information when it is free, but this fraction drops by 23 percentage points when information costs $\$ 0.10$. Since these individuals value the donation between $\$ 2.5$ and $\$ 10$, we first examine whether their behavior is similar to that of individuals in the Self-10 and Self- 5 treatments. Subjects with a WTD of 10 should behave as in Self-10, and subjects with a WTD of 5 should act like subjects in Self-5. Comparing those subjects who display a WTD of $10(N=26)$ in the Donation treatment and subjects in the Self-10 treatment, we do not find a difference on willingness to pay for information, which is $\$ 0.83$ in both cases $(p$-value $=0.9773)$. The number of subjects with a WTD of 5 in the Donation treatment is small $(N=8)$, and hence such a comparison cannot be made. Yet, the behavior of subjects with a WTD between 2.5 and 7.5 shown in Figure 5b displays a significant kink in information demand to the right of $\$ 0$, which is not observed in the Self-5 (or Self-10) treatments.

This kink could be explained for two reasons. The first is risk preferences in the donation domain. If individuals are sufficiently risk seeking, when information becomes costless, they could prefer to choose the envelope without information. Indeed, about a third of the subjects $(31.4 \%)$ who do not demand information when it is costly, opt for the closed envelope instead. ${ }^{19}$

The second reason for the kink is that moral norms regarding information seeking

\footnotetext{
${ }^{19}$ Among the selected sample of individuals who no longer demand information when it costs $\$ 0.10$, we find that 30 individuals choose the $\$ 2.5$ payment, while 9 choose the closed envelope. To examine whether those subjects who switch to the closed envelope are relatively risk loving with respect to the donation, we explore the ratio of their valuation of the donation with certainty, relative to their valuation of the donation with uncertainty. A risk neutral individual would exhibit a ratio of 2 . We find that on average the ratio for all subjects is 2.33 (s.d. 2.78). For the subjects who switched it is 1.74 (s.d. 0.66). Thus, indeed, we find some indication of risk lovingness in these subjects.
} 
may differ from those regarding information avoidance. Though this is not captured in our model, when information is costly, choosing not to pay for information may be considered more morally appropriate than choosing to pay to avoid information. In the next section, we collect data on the moral norms regarding information avoidance. These norms turn out to be rather inelastic to the price of information. Nevertheless, information demand is considered somewhat less important when information becomes costly. This norm change may contribute to the kink around $\$ 0$ for subjects who have a high valuation for the certain donation.

In addition to the individual's valuation of the $\$ 10$ donation, several individual characteristics may explain an individual's willingness to pay for information. In Table 3 we examine the determinants of information preferences in the Donation treatment. One important preference is the individual's value of a $\$ 10$ donation that occurs only with $50 \%$ chance. To measure how much the individual's value drops when uncertainty cannot be removed, we compare the monetary equivalent of a $\$ 10$ donation with certainty and the one with $50 \%$ chance. If the equivalent with uncertainty is less than half of the equivalent with certainty, we classify the individual as risk averse (with respect to the donation). We do not observe that the change in the donation valuation when it is uncertain, relative to when it is certain, is related to information demand. Additional characteristics that can explain information decisions are the score on the Monitors-Blunters Scale and the Machiavellianism scale, as well as gender, age, education and frequency of work on Mturk. We find that the Monitors-Blunters Scale is associated with information avoidance, but we do not find evidence that the Machiavellianism scale or individual socio-demographic characteristics explain information choices.

\subsection{Experiment 2: Social Norms Regarding Information Avoidance}

Figure 6 displays the fraction of individuals who considers getting the $\$ 2.5$ payment morally appropriate, as well as the fraction who considers demanding information by opening the envelope morally appropriate. An action is defined as morally ap- 
Table 3: Determinants of information demand in the Donation treatment

(1) (2)

Willingnes to pay for information

\begin{tabular}{lrrr} 
Monetary equivalent of $\$ 10$ donation & $0.1625^{* * *}$ & $0.1653^{* * *}$ & $0.1640^{* * *}$ \\
& $(0.0208)$ & $(0.0208)$ & $(0.0213)$ \\
Risk averse & 0.1168 & 0.0992 & 0.0942 \\
& $(0.1485)$ & $(0.1482)$ & $(0.1496)$ \\
Monitors-Blunters Scale Score & & $0.0273^{* *}$ & $0.0277^{* *}$ \\
Mach IV Score & $(0.0135)$ & $(0.0138)$ \\
& & 0.0416 & 0.0291 \\
Female & $(0.1179)$ & $(0.1227)$ \\
Age & & & -0.0623 \\
High school degree or higher & & & $(0.1206)$ \\
Works every day on Mturk & & & 0.0005 \\
& & & $(0.0056)$ \\
Constant & & & -0.0744 \\
& & & $0.1188)$ \\
Observations & $-0.7416^{* * *}$ & $-0.9966^{* * *}$ & $-0.9651^{* *}$ \\
R-squared & $(0.0715)$ & $(0.3518)$ & $(0.4721)$ \\
\hline
\end{tabular}

Notes: This table examines the determinants of willingness to pay for information in the Donation treatment. The dependent variable takes values from -2 to 2 , depending on when the individual chooses to switch from obtaining information to not obtaining information. The monetary equivalent of $\$ 10$ donation is the individual's valuation of the donation. Risk averse is a dummy variable that takes value 1 if the individual values a donation opportunity with $50 \%$ chance less than half of her monetary equivalent of a certain donation. Standard errors shown in parentheses. ${ }^{* * *} p<0.01,{ }^{* *} p<0.05, *$ $p<0.1$

propriate if an individual considers it somewhat or very morally appropriate. ${ }^{20,21}$

On average, less than a third of subjects considers avoiding information and

\footnotetext{
${ }^{20}$ Alternatively, we could measure moral appropriateness ratings by giving a rating as very morally inappropriate a value of -1 , a rating as somewhat morally inappropriate a value of $-1 / 3$, a rating as somewhat morally appropriate a value of $1 / 3$ and a rating as very morally appropriate a value of 1 (see also, Krupka and Weber, 2013). The results are qualitatively similar. Furthermore, we also elicited the moral appropriateness of choosing the envelope without knowing whether it contains a donation for certain. A large majority of subjects consider such action morally appropriate. Detailed results for all actions are presented in Appendix C.

${ }^{21}$ In the Norms treatment, we also elicited the moral appropriateness of donating versus acting selfishly. When faced with a certain $\$ 10$ donation, $78 \%$ of individuals consider it morally inappropriate not to donate $\$ 10$ (and forgo $\$ 2.5$ ). When faced with a $50 \%$ chance of a $\$ 10$ donation, $66.7 \%$ consider it morally inappropriate not to donate. These results are broadly in line with existing research evaluating social norms around sharing decisions (e.g., Krupka and Weber, 2013).
} 


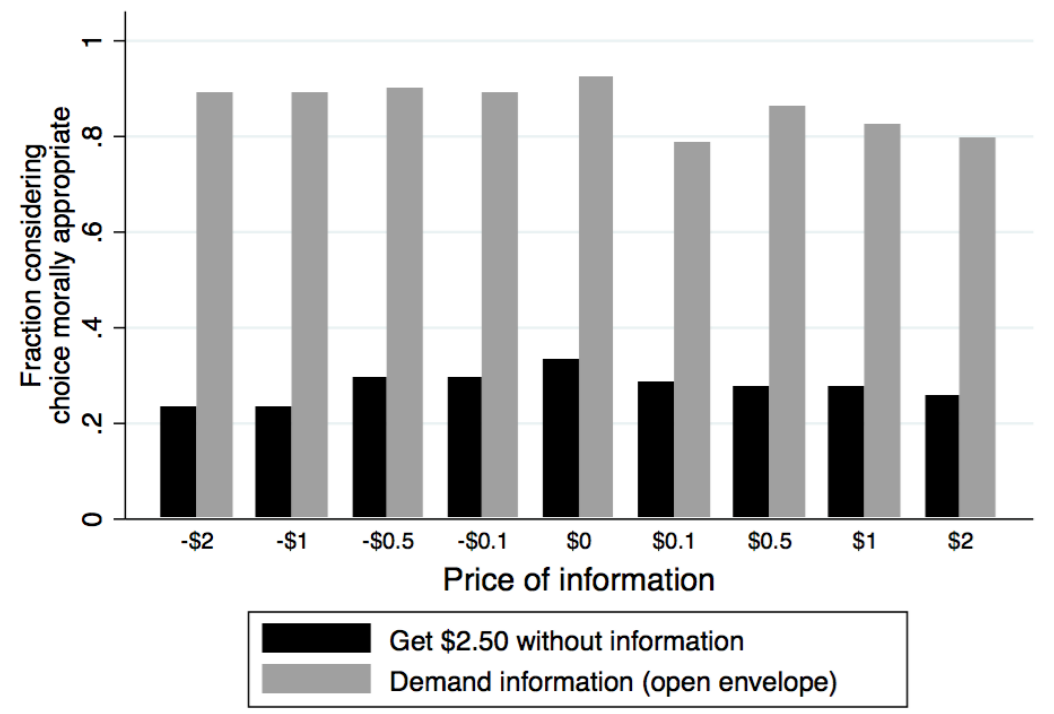

Figure 6: Social Norms regarding Information Avoidance

choosing the $\$ 2.50$ payment very or somewhat morally appropriate. By contrast, over $70 \%$ of individuals consider seeking information very or somewhat morally appropriate. Overall, the moral inappropriateness of each action in the envelope game shows relatively little sensitivity to price. Yet when information is costly, the moral norm to obtain information is significantly weakened, which may explain why individuals demand less information in that case. Table 4 presents the results of a linear probability model on the evaluation of each action as morally appropriate. Moral appropriateness of demanding information does not vary significantly with the price of information, but it exhibits a kink around a price of $\$ 0$. If information is costly, demanding information is 8 percentage points less likely to be considered morally appropriate. This result provides an explanation for the kink in information demand when price increases from $\$ 0$ to $\$ 0.10$, documented in Experiment 1.

\subsection{Experiment 2: The Impact of Information about Social Norms}

Does the provision of the collected information on social norms reduce moral ignorance? Figure 7 depicts the demand curve for information when individuals receive social norm information and when they do not. Avoidance in the NoNorm treatment is shown in the black solid line. Avoidance in Norm-Avoid is depicted by the grey 
Table 4: Moral Appropriateness

\begin{tabular}{|c|c|c|c|}
\hline Action: & $\begin{array}{c}(1) \\
\text { Get } \$ 2.5\end{array}$ & $\begin{array}{c}(2) \\
\text { Morally Appropriate } \\
\text { Demand Information }\end{array}$ & $\begin{array}{l}(3) \\
\text { All }\end{array}$ \\
\hline Price (of Information) & $0.0450^{* *}$ & 0.0087 & $\begin{array}{c}0.0087 \\
(0.0140)\end{array}$ \\
\hline Costly Information & $\begin{array}{l}-0.0257 \\
(0.0241)\end{array}$ & $\begin{array}{c}-0.0827^{* *} \\
(0.0346)\end{array}$ & $\begin{array}{c}-0.0827^{* *} \\
(0.0346)\end{array}$ \\
\hline Costly Information X Price & $\begin{array}{c}-0.0595^{* *} \\
(0.0297)\end{array}$ & $\begin{array}{c}-0.0170 \\
(0.0243)\end{array}$ & $\begin{array}{l}-0.0170 \\
(0.0243)\end{array}$ \\
\hline Get $\$ 2.5$ & & & $\begin{array}{c}-0.5955^{* * *} * \\
(0.0492)\end{array}$ \\
\hline Price X Get $\$ 2.5$ & & & $\begin{array}{c}0.0362 \\
(0.0219)\end{array}$ \\
\hline Costly Information X Get $\$ 2.5$ & & & $\begin{array}{c}0.0570 \\
(0.0458)\end{array}$ \\
\hline Costly Information X Price X Get $\$ 2.5$ & & & $\begin{array}{c}-0.0425 \\
(0.0366)\end{array}$ \\
\hline Constant & $\begin{array}{c}0.3108^{* * *} \\
(0.0440)\end{array}$ & $\begin{array}{c}0.9063^{* * *} \\
(0.0233)\end{array}$ & $\begin{array}{c}0.9063^{* * *} \\
(0.0233)\end{array}$ \\
\hline Observations & 918 & 918 & 1,836 \\
\hline R-squared & 0.0033 & 0.0150 & 0.3564 \\
\hline Nr. of subjects & 102 & 102 & 102 \\
\hline
\end{tabular}

Notes: This table examines the impact of price on the likelihood that getting $\$ 2.5$ (private payment) and demanding information is considered very or somewhat morally appropriate. The dependent variable takes value 1 if the individual considers getting $\$ 2.5$ (private payment) or demanding information very morally appropriate or somewhat morally appropriate. Robust clustered standard errors shown in parentheses. ${ }^{* * *} p<0.01,{ }^{* *} p<0.05,{ }^{*} p<0.1$

dashed line and in Norm-Seek by the grey solid line.

On average, we do not observe a significant effect of social norm information on moral ignorance. Table 5 presents the results from estimating the effect of norm information on the likelihood to avoid information. We observe that ignorance decreases directionally by 1 to 4 percentage points, a change that is not significantly different from zero.

As observed in Experiment 1, information avoidance again displays a significant kink around $\$ 0$ (of 32 percentage points) in the NoNorm treatment. This kink is similar when information about social norms is provided. The data thus confirm that a shift from small monetary costs to small monetary rewards for seeking information can decrease moral ignorance in a pronounced and robust way.

When exploring the effects of social norm information on information demand, 


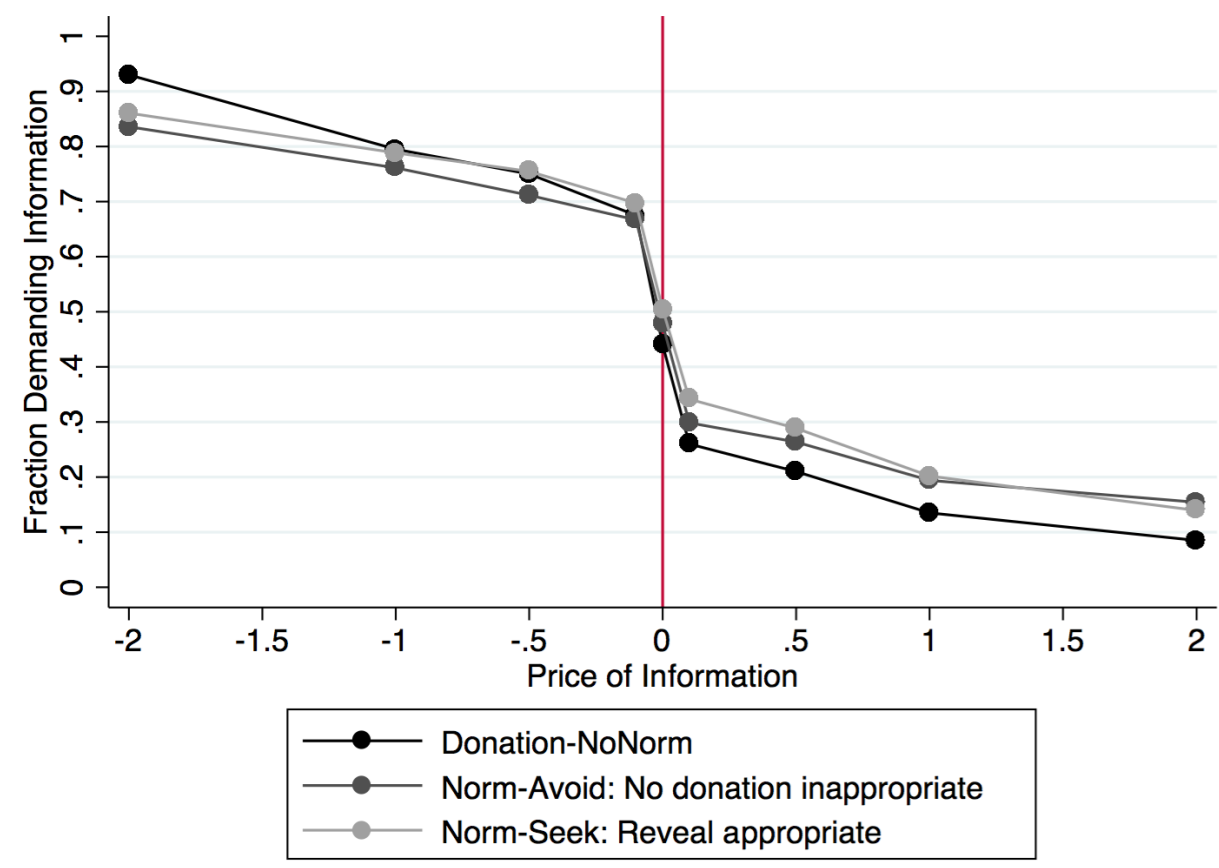

Figure 7: Information Avoidance in Experiment 2, by treatment

we find that social norm information decreases price sensitivity. The results are displayed in column (3) of Table 5. First, price sensitivity decreases significantly, by ca. 5 percentage points, when individuals are paid to obtain information in both Norms treatments. Descriptively, a higher share of individuals choose not to obtain information even if they are paid $\$ 2$ in the Norm-Avoid and Norm-Seek treatments. Second, when individuals have to pay to obtain information, they are also less price sensitive (significantly so in the Norm-Seek treatment). For this range of prices, there is a directional upward shift in the demand curve, as individuals demand information more often. This effect is consistent with social norm information increasing individuals' valuation of the donation.

To examine whether social norm information affects subjects' willingness to donate (WTD), we compare the monetary equivalent of a $\$ 10$ donation across treatments. It increases by $\$ 0.71$ ( $t$-test, $p$-value $=0.06)$ and $\$ 0.68(t$-test, $p$-value $=0.08)$ in the Norm-Avoid and Norm-Seek treatments, respectively, compared to the NoNorm treatment. ${ }^{22}$ In terms of our model, we thus observe an increase in the individual's

\footnotetext{
${ }^{22}$ In line with this result, we find that conditional on demanding information, individuals who learn that the envelope contains a $\$ 10$ donation donate $67 \%$ of the time in the NoNorm treatment, $77 \%$ in the Norm-Avoid treatment, and $74 \%$ in the Norm-Seek treatment. The increase is marginally significant ( $p=0.051$ and $p=0.063$, respectively).
} 
Table 5: Information Demand in Response to Social Norm Information

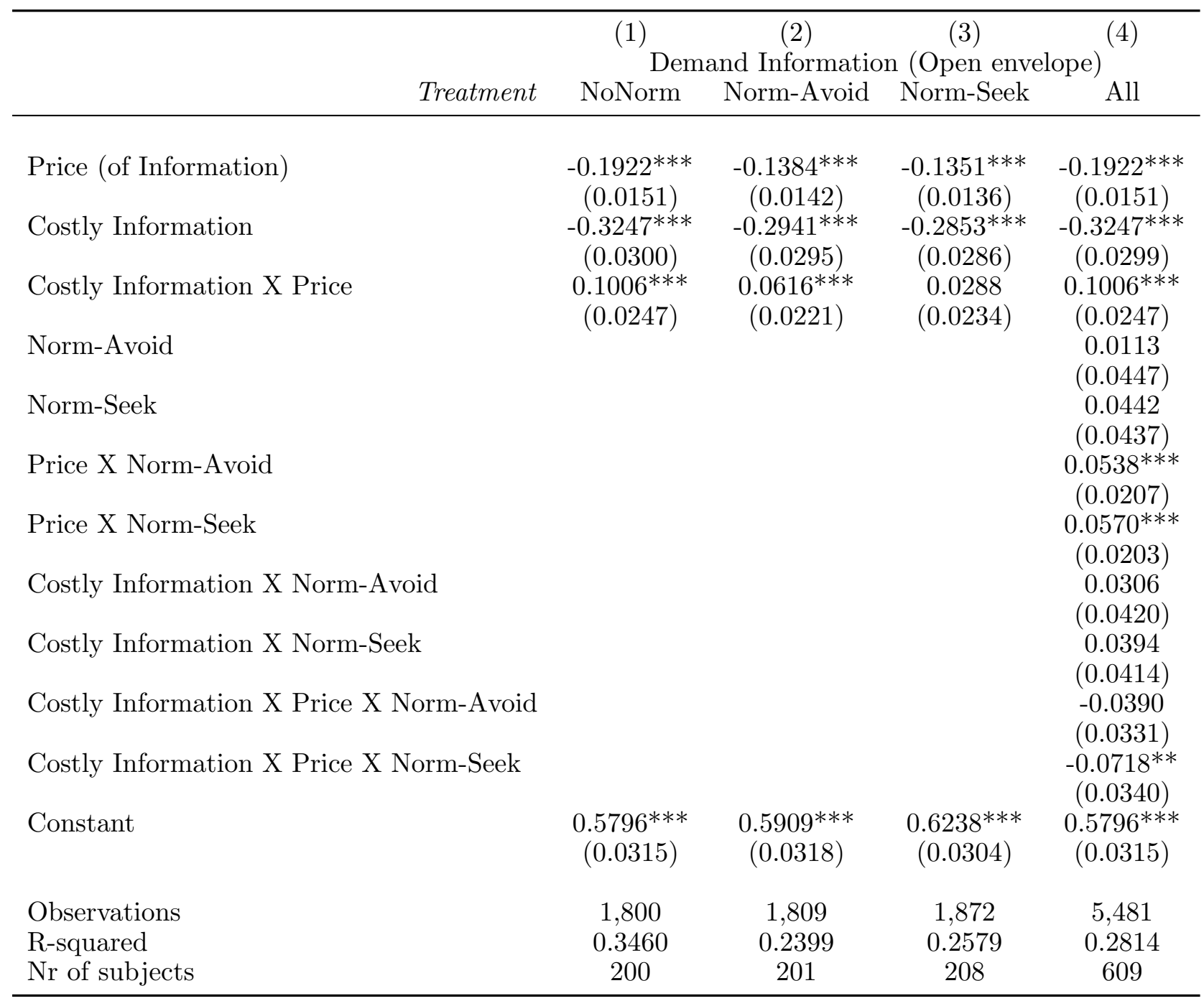

Notes: This table examines the impact of price on information demand in the NoNorm, Norm-Avoid and Norm-Seek treatments. The dependent variable takes value 1 if the individual demands information (opens envelope). Robust clustered standard errors shown in parentheses. ${ }^{* * *} p<0.01,{ }^{* *} p<0.05,{ }^{*}$ $p<0.1$

WTD (i.e., an increase in $\alpha$ ).

In the theoretical framework, we argued that norm provision may operate in two ways: First, an increase in WTD could lead to more demand for information in the envelope game. However, there may be a second, partly opposing effect. If moral costs of rejecting a certain donation increase from norm provision as well, i.e., if the moral discounting via $\beta$ becomes more drastic, effects could be partly offset. This could only reduce the demand for information for rather selfish individuals. Consis- 
tent with this prediction, the directional downward shift in the demand function is only observed when the price of information is negative. When the price of information is positive, only individuals with an interest in donating open the envelope anyway. Among them, we see a weak increase in demand for information. Therefore, norm provision only increases information demand directionally when getting information is costly.

All in all, we find that norm provision increases willingness to donate, but does not increase information demand on average. It only directionally increases information demand among rather altruistic subjects.

\section{$5 \quad$ External Validity of Information Preferences in the Envelope Game}

The results thus far reveal that information demand about a moral dilemma, such as that studied in the envelope game, is highly elastic to price, but rather inelastic to social norm information. An important question is whether information demand in the envelope game is predictive of information demand in other moral dilemmas. For this purpose, we developed a follow-up task on information demand about animal welfare in dairy production, which ran 7 to 10 days after individuals participated in the morally relevant envelope game. We found that a majority of participants (65\%) choose to watch the informational video about cows' living conditions. The main question is whether the choice to watch this video is related to subjects' willingness to pay to avoid information in the envelope game.

Table 6 shows the relationship between willingness to pay to avoid information in the envelope game and the choice to watch the informational video. As can be seen, individuals with a stronger willingness to pay to avoid information in our experimental task are also less likely to watch the video about cows' living conditions. This provides evidence in support of the external validity of informational choices in our main experiment. ${ }^{23}$

The rate of avoidance varies with social norm information. In the NoNorm treatment, the share of individuals who watch the video is $76.9 \%$. It is $68.8 \%$ in the Norm-Avoid treatment, and $74.3 \%$ in the NormReveal treatment. As shown in column (2) of Table 4, the Norm-Avoid treatment led to an increase in avoidance of

\footnotetext{
${ }^{23}$ Qualitatively similar results are obtained if we study the relationship between the share of correct answers to the questions about the video and information avoidance in the donation setting.
} 
Table 6: External validity of informational preferences

\begin{tabular}{lcc}
\hline & $\begin{array}{l}\text { Likelihood of watching } \\
\text { video about cows' living } \\
\text { conditions } \\
(1)\end{array}$ & $(2)$ \\
\hline Willingness to pay to avoid information & $-0.0582^{* * *}$ & $-0.0582^{*}$ \\
Norm-Avoid Treatment & $(0.0157)$ & $(0.0314)$ \\
Norm-Seek Treatment & & $-0.0792^{*}$ \\
Norm-Seek X Willingness to pay to avoid information & & $-0.0460)$ \\
Norm-Seek X Willingness to pay to avoid information & & $(0.0470)$ \\
& & 0.0094 \\
Observations & & $-0.0403)$ \\
& 533 & $(0.0424)$ \\
\hline
\end{tabular}

Notes: This table reports marginal effects from probit regressions on the likelihood of watching the informational video about cows' living conditions. The variable willingness to pay to avoid information is measured by the price of information avoidance at the point at which the individual switches from demanding information to avoiding information. Norm-Avoid and Norm-Seek treatment are treatment dummies for the corresponding treatment in Experiment 2. Robust clustered standard errors shown in parentheses. ${ }^{* * *} p<0.01,{ }^{* *} p<0.05,{ }^{*} p<0.1$

the video. While the effect is comparatively small and is exploratory, this suggests that social norm interventions should carefully measure short-run as well as long-run impacts, to fully capture potential spillovers onto other behaviors.

\section{Conclusion}

This paper investigates the elasticity of preferences for and against morally relevant information. We propose a parsimonious model in which individuals suffer moral costs from rejecting a certain moral outcome, which can explain why rather selfish individuals prefer moral ignorance.

Using morally neutral benchmarks, we identify the differences between morally neutral and morally relevant information avoidance, and show that the moral relevance of the decision leads to significantly more information avoidance. In the moral context, small monetary incentives to seek information have significant impact on information demand. The demand curve for moral information exhibits a pronounced kink around zero, but price sensitivity is much weaker for larger incentives. 
This indicates that removing any (small) monetary costs of information and introducing small monetary incentives for information seeking can reduce moral ignorance roughly by 50 percent. Hence, if feasible, such an intervention could be well suited to foster information seeking. By contrast, larger monetary incentives would have comparatively little impact on reducing moral ignorance, and come at a much larger cost.

In policy circles, costless interventions such as moral "nudges" are often discussed as interventions to reduce unethical behavior. Our findings with two different framings of norms suggest that norm interventions likely perform differently when applied to encouraging information demand, compared to encouraging ethical behavior. Moral nudges in the form of norm provision can indeed increase valuations of the moral outcome. Yet, their impact on curbing moral ignorance is limited. Possibly, norms increase the moral costs from rejecting moral outcomes and thereby foster ignorance for some subjects.

\section{References}

[1] Albrecht, Konstanze, Florentin Krämer and Nora Szech (2017). "Animal Welfare and Human Ethics: A Personality Study". CESifo Working Paper No. 6609.

[2] Andreoni, James, and Lise Vesterlund (2001). "Which is the fair sex? Gender differences in altruism." Quarterly Journal of Economics 116 (1), 293-312.

[3] Andreoni, James, Justin M. Rao, and Hannah Trachtman (2017). "Avoiding the ask: a field experiment on altruism, empathy, and charitable giving". Journal of Political Economy, 125 (3): 625-653.

[4] American Society for the Prevention of Cruelty to Animals (2016). "New Research Finds Vast Majority of Americans Concerned about Farm Animal Welfare, Confused by Food Labels and Willing to Pay More for Better Treatment," Press Release.

[5] Bandura, Albert (2016). Moral Disengagement: How People Do Harm and Live With Themselves. New York: Worth Publishers.

[6] Bartling, Björn, Florian Engl and Roberto A. Weber (2014). "Does Willful Ignorance Deflect Punishment? An Experimental Study." European Economic 
Review 70, 512-524.

[7] Bénabou, Roland, and Jean Tirole (2011). "Identity, Morals and Taboos: Beliefs as Assets." Quarterly Journal of Economics 126(2): 805-55.

[8] Bicchieri, Cristina and Erte Xiao (2009). "Do the Right Thing: But Only if Others Do So." Journal of Behavioral Decision Making 22 (2), 191-208.

[9] Bundesministerium für Ernährung und Landwitschaft [German Ministry of Nutrition and Agriculture] (2016). "Deutscher Ernährungsreport [German nutrition report]"

[10] Cain, Daylain M. and Jason Dana (2012). "Paying People to Look at the Consequences of Their Actions." Working paper.

[11] Christie, R., and F. L. Geis. (1970) Studies in Machiavellianism. New York and London: Academic Press.

[12] Cialdini, Robert B. and Noah J. Goldstein (2004). "Social Influence: Compliance and Conformity." Annual Review of Psychology 55, 591-621.

[13] Dana, Jason (2006). "Strategic Ignorance and Ethical Behavior in Organizations." In Ethics in Groups: Research on Managing Groups and Teams, Volume 8, edited by Ann E. Tenbrunsel, 39-57. Bingley: Emerald Group Publishing.

[14] Dana, Jason, Roberto A. Weber, and Jason Xi Kuang (2007). "Exploiting Moral Wriggle Room: Experiments Demonstrating an Illusory Preference for Fairness." Economic Theory 33(1): 67-80.

[15] DellaVigna, Stefano, John A. List, and Ulrike Malmendier (2012). "Testing for altruism and social pressure in charitable giving." Quarterly Journal of Economics, 127(1), 1-56.

[16] Exley, Christine (2015). "Excusing Selfishness in Charitable Giving: The Role of Risk." Review of Economic Studies 83, 587-628.

[17] Exley, Christine (2017). "Using Charity Performance Metrics as an Excuse Not to Give." Working paper.

[18] Exley, Christine and Ragan Petrie (2018). "The Impact of a Surprise Donation Ask." Journal of Public Economics 158, 152-167. 
[19] Feiler, Lauren (2014). "Testing Models of Information Avoidance with Binary Choice Dictator Games." Journal of Economic Psychology 45: 253-67.

[20] Frey, Bruno and Stephan Meier (2009). "Social Comparison and Pro-social Behavior: Testing 'Conditional Cooperation' in a Field Experiment." American Economic Review 94 (5), 1717-1722.

[21] Freddi, Eleonora (2017). "Do People Avoid Morally Relevant Information? Evidence from the Refugee Crisis." Working paper.

[22] Ganguly, Ananda R., and Joshua Tasoff (2017). "Fantasy and Dread: The Demand for Information and the Consumption Utility of the Future." Management Science 63 (12), 4037-4060.

[23] Golman, Russell, David Hagmann, and George Loewenstein (2016). Information Avoidance. Journal of Economic Literature 55 (1), 96-135.

[24] Grossman, Zachary (2014). "Strategic Ignorance and the Robustness of Social Preferences." Management Science 60 (11), 2659-2665.

[25] Grossman, Zachary, and Joël van der Weele (2017). "Self-Image and Willful Ignorance in Social Decisions." Journal of the European Economic Association, forthcoming.

[26] Guerrero, Alexander A. (2007). "Don't Know, Don't Kill: Moral Ignorance, Culpability, and Caution." Philosophical Studies 136, 59-97.

[27] Hallsworth, M., John, Robert Metcalfe and Ivo Vlaev, I. (2017). "The behavioralist as tax collector: Using natural field experiments to enhance tax compliance." Journal of Public Economics 114, 14-31.

[28] Hertwig, Ralph and Christoph Engel (2016). "Homo Ignorans Deliberately Choosing Not to Know." Perspectives on Psychological Science 11 (3), 359372 .

[29] Huck, Steffen, Nora Szech and Lukas Wenner (2018). "More Effort with Less Pay: On Information Avoidance, Belief Design and Performance." KIT Working Paper.

[30] Jackall, Robert (1988). Moral mazes: The world of corporate managers. Oxford: Oxford University Press. 
[31] Karlsson Niklas, George Loewenstein, and Duane Seppi. 2009. "The Ostrich Effect: Selective Attention to Information." Journal of Risk and Uncertainty 38 (2): $95 ? 115$.

[32] Krupka, Erin L. and Roberto A.Weber (2013). "Identifying Social NormsUsing Coordination Games. Why Does Dictator Game Sharing Vary?" Journal of the European Economic Association 11, 495-524.

[33] Larson, Tara, and C. Monica Capra (2009). "Exploiting Moral Wiggle Room: Illusory Preference for Fairness? A Comment." Judgment and Decision Making 4(6), 467-474.

[34] Martin, Richard and John Randal, 2008. "How is donation behaviour affected by the donations of others?" Journal of Economic Behavior and Organization $67,228-238$.

[35] Matthey, Astrid and Tobias Regner (2011). "Do I Really Want to Know? A Cognitive Dissonance-Based Explanation of Other-Regarding Behavior." Games, 2, 114-135.

[36] McAuliffe, Katherine, Nichola J. Raihanic and Yarrow Dunham (2017). "Children are sensitive to norms of giving." Cognition 167, 151-159.

[37] Miller, Suzanne M. (1987). "Monitoring and Blunting: Validation of a questionnaire to assess styles of information seeking under threat." Journal of Personality and Social Psychology, 52(2), 345-353.

[38] Niehaus, Paul (2014). A Theory of Good Intentions. Working paper.

[39] OECD (2018). Behavioural Insights for Public Integrity Harnessing the Human Factor to Counter Corruption. OECD Public Governance Reviews, OECD Publishing, Paris.

[40] Onwezen, Marleen C. and Cor N. van der Weele (2016). "When indifference is ambivalence: Strategic ignorance about meat consumption." Food Quality and Preference 52, 96-105.

[41] Oster, Emily, Ira Shoulson, and E. Ray Dorsey (2013). "Optimal Expectations and Limited Medical Testing: Evidence from Huntington Disease." American Economic Review 103 (2): 804?30. 
[42] Rayner, Steve (2012). "Uncomfortable Knowledge: The Social Construction of Ignorance in Science and Environmental Policy Discourses" Economy and Society 41 (1), 107-25.

[43] Rosen, G. (2003). "Culpability and ignorance." Proceedings of the Aristotelian Society, 103 (1), 61-84.

[44] Schultz, P. Wesley, Jessica M. Nolan, Robert B. Cialdini, Noah J. Goldstein and Vladas Griskevicius (2007). "The Constructive, Destructive and Reconstructive Power of Social Norms." Psychological Science 18 (5), 429-434.

[45] Shang, Jen and Rachel Croson. (2009). "A Field Experiment in Charitable Contribution: The Impact of Social Information on the Voluntary Provision of Public Goods." Economic Journal 119, 1422-1439.

[46] Sicherman, Nachum, George Loewenstein, Duane J. Seppi, and Stephen P. Utkus (2016). "Financial Attention." Review of Financial Studies 29 (4): 863-897.

[47] te Velde, Hein, Noelle Aarts and Cees van Woerkum (2002). "Dealing with Ambivalence: Farmers' and Consumers' Perceptions of Animal Welfare in Livestock Breeding." Journal of Agricultural and Environmental Ethics 15, 203-219.

[48] van der Weele, Joël (2014) "Inconvenient Truths: Determinants of Strategic Ignorance in Moral Dilemmas." Working paper.

[49] Zane, Daniel M., Julie R. Irwin and Rebecca Walker Reczek (2016). "Do less ethical consumers denigrate more ethical consumers? The effect of willful ignorance on judgments of others. Journal of Consumer Psychology 26 (3), 337-349.

[50] Zimmerman, Michael J. (1997). "Moral responsibility and ignorance." Ethics, 107 (3), 410-426. 


\section{Appendices}

\section{A Instructions}

Below we present the instructions for the Donation treatment in Experiment 1. The Self-5 and Self-10 treatments had the same instructions except that the $\$ 10$ donation was replaced by a $\$ 5$ or $\$ 10$ payment for the individual. In Experiment 2 we added information on social norms at the end of the instructions, as indicated in brackets below.

In this study, you make decisions involving money for you and a donation to the Malaria Consortium in your name.

Your donation takes place via an envelope.

The envelope either contains: a $\$ 10$ donation on your behalf with $50 \%$ chance, or no donation with $50 \%$ chance

page break

In this part, you do not know what the envelope contains. You decide whether to get $\$ 2.50$, get the envelope, or reveal what the envelope contains first.

You will make 9 decisions. In each decision you have three options:

(a) Get $\$ 2.50$ : then, you get $\$ 2.50$.

(b) Get the envelope: then, you donate what the envelope contains, which you do not know.

(c) Reveal what the envelope contains first: then, you are shown whether the envelope contains a $\$ 10$ donation on your behalf or no donation. After being informed of the envelope's content, you decide either to get $\$ 2.50$ or get the envelope.

In each decision, you may receive an additional amount for choosing option (c) 'Reveal what the envelope contains first', or you may receive an additional amount for NOT choosing option (c), that is not 'revealing what the envelope contains first', and choosing options (a) or (b). 
Across the 9 decisions, this additional amount you receive varies, from $\$ 2$ for revealing what the envelope contains to $\$ 0$, and from $\$ 0$ to $\$ 2$ for NOT revealing what the envelope contains.

You will not know which is the 'decision that counts' until the end of the study. Because the computer is making a random draw, any of the choices could be the 'decision that counts.' Therefore, you should think carefully about the choice you make in each question.

page break

Remember, the envelope either contains:

a $\$ 10$ donation on your behalf with $50 \%$ chance, or

no donation with $50 \%$ chance.

In what follows you will be shown an example and will be asked to answer several questions, before making your decisions.

page break

\section{EXAMPLE}

As an example, let us consider question 5. In this question, you receive $\$ 0$ for revealing what the envelope contains, and $\$ 0$ for not revealing what the envelope contains. The question is shown below.

5. If you get $\$ 0$ for revealing and $\$ 0$ for not revealing what the envelope contains first, what do you choose?

(a) Get $\$ 2.50$

(b) Get the envelope

(c) Reveal what the envelope contains

If you choose '(a) get $\$ 2.50$ ', you get $\$ 2.50$.

If you choose '(b) get the envelope', you donate $\$ 10$ with $50 \%$ chance or donate $\$ 0$ with $50 \%$ chance. 
If you choose '(c) reveal what the envelope contains', you learn what is inside the envelope. Two cases can then happen:

1. The envelope contains a $\$ 10$ donation on your behalf. Then you choose between:

Get $\$ 2.50$ or

Donate $\$ 10$.

2. The envelope contains no donation. Then you choose between:

Get $\$ 2.50$ or

Donate $\$ 0$.

Thus, choosing (c) brings you to another choice. This choice is either between a monetary amount for you and a donation on your behalf or between a monetary amount for you and no donation in your name.

\section{CONTROL QUESTIONS}

As an exercise, let us consider question 1.

The envelope either contains a $\$ 10$ donation with $50 \%$ chance or no donation with $50 \%$ chance.

In question 1 , you receive $\$ 2$ for revealing what the envelope contains. You choose from these options:

(a) Get $\$ 2.50$.

(b) Get the envelope.

(c) Reveal what the envelope contains (plus $\$ 2$ for revealing what the envelope contains).

Suppose you choose (a). What happens?

I get $\$ 0$ 
I get $\$ 2.50$

Suppose you choose (b). What happens?

I get $\$ 4.50$

I donate what is in the envelope.

Suppose you choose (c). What happens?

I learn what is inside the envelope and then decide between the envelope and $\$ 2.50$. I either decide between a $\$ 10$ donation on my behalf or $\$ 2.50$ for me, or I decide between a $\$ 0$ donation or $\$ 2.50$ for me. I also get $\$ 2$ for choosing to reveal what is in the envelope.

I do not learn what is inside the envelope and get $\$ 0$.

page break

Now you will make your decisions for this part.

In each question, the chance that the envelope contains a $\$ 10$ donation is $50 \%$. So, the envelope's content varies for each question according to chance.

One of your decisions may be the 'decision that counts'. So please decide carefully!

page break

[Treatment Norm-SeekInfo: NOTE: More than 70\% of MTurkers who evaluated the actions in this part consider it MORALLY APPROPRIATE to choose the option 'Reveal what the envelope contains' first.]

[Treatment Norm-AvoidInfo: NOTE: More than 70\% of MTurkers who evaluated the actions in this part consider it MORALLY INAPPROPRIATE to choose the option 'Get $\$ 2.5$ ' without revealing what the envelope contains first.] 


\section{B Elicitation of Control Measures}

After the main part of the experiment, we elicited the monetary equivalent of a certain $\$ 10$ donation, by asking the individual to make eight binary choices between the donation and payments to her that increased from $\$ 0.10$ to $\$ 10$. Each choice between a private payment and the donation was presented in a separate screen, and across screens the value of the private payment increased. Thereafter, we elicited the monetary equivalent of a $\$ 10$ donation that occurs with a $50 \%$ chance. Individuals made again eight binary choices, each between the potential donation and a payment that increased from $\$ 0.01$ to $\$ 5$. These choices were elicited in the Donation treatment in Experiment 1 and all treatments in Experiment 2.

For each individual, we calculate her monetary equivalent of a certain (uncertain) donation as the maximum value of the payment to her that she was willing to give up instead of the donation. As shown in Table B.1., on average, individuals' monetary equivalent of a certain $\$ 10$ donation was $1.91(s d=2.94)$, while it was $0.69(s d=0.89)$ for a $50 \%$ chance of a $\$ 10$ donation in Experiment 1.

Table B.1: Control Measures and Sample Characteristics

\begin{tabular}{|c|c|c|c|c|c|c|c|}
\hline & & \multicolumn{3}{|c|}{ Experiment 1} & \multicolumn{3}{|c|}{ Experiment 2} \\
\hline & & Donation & Self-5 & Self-10 & NoNorm & Norm-Avoid & Norm-Seek \\
\hline \multirow[t]{2}{*}{$\begin{array}{l}\text { Monetary equivalent of: } \\
\text { (1) } \$ 10 \text { Donation }\end{array}$} & Mean & 1.91 & - & - & 2.92 & 3.60 & 3.56 \\
\hline & $\mathrm{SD}$ & 2.94 & & & 3.48 & 3.78 & 3.92 \\
\hline (2) $\$ 10$ Donation/Self & Mean & 0.69 & 1.40 & 2.59 & 0.78 & 0.81 & 0.72 \\
\hline payment, with $p=0.5$ & $\mathrm{SD}$ & 0.82 & 0.76 & 1.83 & 0.88 & 0.97 & 0.89 \\
\hline \multicolumn{8}{|l|}{ Subject characteristics } \\
\hline Female & Mean & $45.9 \%$ & $42.9 \%$ & $46.7 \%$ & $55.0 \%$ & $51.2 \%$ & $52.9 \%$ \\
\hline Age & Mean & 36.5 & 37.6 & 35.3 & 36.3 & 35.6 & 38.0 \\
\hline High school graduate & Mean & $40.5 \%$ & $30.6 \%$ & $44.1 \%$ & $36.0 \%$ & $31.8 \%$ & $33.2 \%$ \\
\hline On Mturk 7 days a week & Mean & $92.5 \%$ & $91.8 \%$ & $90.8 \%$ & $89.0 \%$ & $86.1 \%$ & $91.8 \%$ \\
\hline
\end{tabular}

In the Self 5 and Self 10 treatments of Experiment 1, we elicited the certainty equivalent of a $\$ 5$ and $\$ 10$ payment that occurred with $50 \%$ chance. We asked the individual to make eight binary choices between the uncertain payment and 
payments to her that increase from $\$ 0.50$ to $\$ 5$ in the Self 5 treatment, and $\$ 1$ and $\$ 10$ in the Self 10 treatment. On average, the certainty equivalent of a $50 \%$ chance of $\$ 5$ was 1.40 , and that of a $50 \%$ chance of $\$ 10$ was 2.59 .

The second part of Table B.1. displays the characteristics of subjects who participated in Experiment 1 and 2, including gender, age, high school graduates and intensity of work at Amazon Mechanical Turk.

\section{Additional Results}

\section{C.1 Experiment 1: Informational choices}

Table C.1 below presents the distribution of choices in Experiment 1. For each price of avoidance we show the percentage of individuals who (a) avoid and choose $\$ 2.50$ ("Choose \$2.50") (b) avoid and donate ("Choose envelope") (c) Seek information ("Open envelope") 
Table C.1: Distribution of choices in Experiment 1

\begin{tabular}{|c|c|c|c|c|}
\hline \multirow[b]{2}{*}{ Price of information } & & \multicolumn{3}{|c|}{ Treatment } \\
\hline & & Donation & Self- 5 & Self-10 \\
\hline \multirow[t]{3}{*}{$-\$ 2$} & Choose $\$ 2.5$ & $14.6 \%$ & $7.5 \%$ & $2.6 \%$ \\
\hline & Choose envelope & $1.0 \%$ & $2.0 \%$ & $2.6 \%$ \\
\hline & Open envelope & $84.4 \%$ & $90.5 \%$ & $94.7 \%$ \\
\hline \multirow[t]{3}{*}{$-\$ 1$} & Choose $\$ 2.5$ & $28.6 \%$ & $18.4 \%$ & $6.6 \%$ \\
\hline & Choose envelope & $2.0 \%$ & $2.0 \%$ & $3.3 \%$ \\
\hline & Open envelope & $69.4 \%$ & $79.6 \%$ & $90.1 \%$ \\
\hline \multirow[t]{3}{*}{ - $\$ 0.50$} & Choose $\$ 2.5$ & $36.7 \%$ & $21.8 \%$ & $10.5 \%$ \\
\hline & Choose envelope & $2.7 \%$ & $4.1 \%$ & $4.6 \%$ \\
\hline & Open envelope & $60.5 \%$ & $74.1 \%$ & $84.9 \%$ \\
\hline \multirow[t]{3}{*}{ - $\$ 0.10$} & Choose $\$ 2.5$ & $42.5 \%$ & $23.1 \%$ & $13.8 \%$ \\
\hline & Choose envelope & $2.7 \%$ & $5.4 \%$ & $5.9 \%$ \\
\hline & Open envelope & $54.8 \%$ & $71.4 \%$ & $80.3 \%$ \\
\hline \multirow[t]{3}{*}{$\$ 0$} & Choose $\$ 2.5$ & $62.6 \%$ & $25.9 \%$ & $15.1 \%$ \\
\hline & Choose envelope & $6.1 \%$ & $8.2 \%$ & $9.9 \%$ \\
\hline & Open envelope & $31.3 \%$ & $66.0 \%$ & $75.0 \%$ \\
\hline \multirow{3}{*}{$\$ 0.10$} & Choose $\$ 2.5$ & $72.8 \%$ & $34.0 \%$ & $19.1 \%$ \\
\hline & Choose envelope & $9.2 \%$ & $6.1 \%$ & $11.2 \%$ \\
\hline & Open envelope & $18.0 \%$ & $59.9 \%$ & $69.7 \%$ \\
\hline \multirow[t]{3}{*}{$\$ 0.50$} & Choose $\$ 2.5$ & $77.2 \%$ & $42.2 \%$ & $21.7 \%$ \\
\hline & Choose envelope & $10.2 \%$ & $7.5 \%$ & $13.2 \%$ \\
\hline & Open envelope & $12.6 \%$ & $50.3 \%$ & $65.1 \%$ \\
\hline \multirow[t]{3}{*}{$\$ 1$} & Choose $\$ 2.5$ & $76.5 \%$ & $59.9 \%$ & $30.9 \%$ \\
\hline & Choose envelope & $12.9 \%$ & $9.5 \%$ & $18.4 \%$ \\
\hline & Open envelope & $10.5 \%$ & $30.6 \%$ & $50.7 \%$ \\
\hline \multirow[t]{3}{*}{$\$ 2$} & Choose $\$ 2.5$ & $76.5 \%$ & $76.2 \%$ & $42.1 \%$ \\
\hline & Choose envelope & $17.3 \%$ & $12.9 \%$ & $23.7 \%$ \\
\hline & Open envelope & $6.1 \%$ & $10.9 \%$ & $34.2 \%$ \\
\hline
\end{tabular}


Individuals who choose to seek information learn whether the envelope actually contains a donation. If subjects learn that the envelope is empty, they choose the $\$ 2.50$ payment to themselves in $93.5 \%$ of the cases. If subjects learn that the envelope contains a $\$ 10$ donation, between $49 \%$ and $100 \%$ choose the donation, as shown in Table C.2. Consistent with selection of those who value the donation opportunity highly into seeking information, the share of those who donate increases as the cost of information avoidance decreases.

Table C.2: Behavior conditional on choosing to seek information

\begin{tabular}{rrrrr}
\hline & \multicolumn{2}{c}{$(\mathrm{a})$} & \multicolumn{2}{c}{$(\mathrm{b})$} \\
Price of information & \multicolumn{2}{c}{$\begin{array}{c}\text { Envelope contains } \$ 10 \text { Donation } \\
\text { \% choose envelope }\end{array}$} & \multicolumn{2}{c}{$\begin{array}{c}\text { Envelope contains nothing } \\
\text { \% choose envelope }\end{array}$} \\
\hline$-\$ 2$ & $49.2 \%$ & 126 & $5.7 \%$ & $\mathrm{~N}$ \\
$-\$ 1$ & $50.5 \%$ & 101 & $1.9 \%$ & 103 \\
$-\$ 0.50$ & $52.1 \%$ & 94 & $4.8 \%$ & 84 \\
$-\$ 0.10$ & $51.3 \%$ & 78 & $2.4 \%$ & 83 \\
$\$ 0$ & $74.5 \%$ & 47 & $6.7 \%$ & 45 \\
$\$ 0.10$ & $87.1 \%$ & 31 & $4.5 \%$ & 22 \\
$\$ 0.50$ & $96.0 \%$ & 25 & $16.7 \%$ & 12 \\
$\$ 1$ & $93.3 \%$ & 15 & $6.3 \%$ & 16 \\
$\$ 2$ & $100.0 \%$ & 7 & $9.1 \%$ & 11 \\
\hline
\end{tabular}

Notes: This table shows the percentage of individuals choosing the envelope in two cases: (a) when the envelope contains a $\$ 10$ donation, and (b) when it is empty. In each case we also show the number of observations.

\section{C.2 Experiment 2: Norms elicitation}

Table C.3 shows individual ratings of moral appropriateness of each action, for each price of avoidance. Panel A focuses on the choice to avoid and choose $\$ 2.50$. Panel $\mathrm{B}$ focuses on the choice to avoid and donate by choosing the envelope. Panel $\mathrm{C}$ focuses on the choice to seek information, by opening the envelope. 
Table C.3: Individual ratings of moral appropriateness of each action

Moral Appropriateness Category Rating

Very morally Somewhat morally Somewhat morally Very morally inappropriate inappropriate appropriate appropriate

Price of information

PANEL A. Choose $\$ 2.50$

$\begin{array}{crrrr}-\$ 2 & 38.24 & 38.24 & 18.63 & 4.9 \\ -\$ 1 & 39.22 & 37.25 & 16.67 & 6.86 \\ -\$ 0.50 & 40.2 & 30.39 & 23.53 & 5.88 \\ -\$ 0.10 & 38.24 & 32.35 & 18.63 & 10.78 \\ \$ 0 & 36.27 & 30.39 & 24.51 & 8.82 \\ \$ 0.1 & 41.18 & 30.39 & 19.61 & 8.82 \\ \$ 0.5 & 38.24 & 34.31 & 19.61 & 7.84 \\ \$ 1 & 40.2 & 32.35 & 17.65 & 9.8 \\ \$ 2 & 43.14 & 31.37 & 17.65 & 7.84 \\ & & & & \\ \text { Total } & 39.43 & 33.01 & 19.61 & 7.95\end{array}$

Price of information

PANEL B. Choose envelope

$\begin{array}{crrrr}-\$ 2 & 0.98 & 3.92 & 54.9 & 40.2 \\ -\$ 1 & 0 & 6.86 & 55.88 & 37.25 \\ -\$ 0.50 & 0 & 6.86 & 54.9 & 38.24 \\ -\$ 0.10 & 2.94 & 5.88 & 50.98 & 40.2 \\ \$ 0 & 1.96 & 7.84 & 47.06 & 43.14 \\ \$ 0.1 & 0 & 9.8 & 44.12 & 46.08 \\ \$ 0.5 & 2.94 & 6.86 & 48.04 & 42.16 \\ \$ 1 & 0 & 7.84 & 50 & 42.16 \\ \$ 2 & 0.98 & 9.8 & 41.18 & 48.04 \\ & & & & \\ \text { Total } & 1.09 & 7.3 & 49.67 & 41.94\end{array}$

Price of information

PANEL C. Open envelope first

\begin{tabular}{crrrr}
\hline$-\$ 2$ & 1.96 & 8.82 & 45.1 & 44.12 \\
$-\$ 1$ & 0.98 & 9.8 & 46.08 & 43.14 \\
$-\$ 0.50$ & 0.98 & 8.82 & 48.04 & 42.16 \\
$-\$ 0.10$ & 0.98 & 9.8 & 42.16 & 47.06 \\
$\$ 0$ & 1.96 & 5.88 & 47.06 & 45.1 \\
$\$ 0.1$ & 3.92 & 17.65 & 43.14 & 35.29 \\
$\$ 0.5$ & 2.94 & 10.78 & 55.88 & 30.39 \\
$\$ 1$ & 6.86 & 10.78 & 49.02 & 33.33 \\
$\$ 2$ & 7.84 & 12.75 & 45.1 & 34.31 \\
& & & & \\
Total & 3.16 & 10.57 & 46.84 & 39.43 \\
\hline
\end{tabular}




\section{C.3 Cases of Risk Aversion and Risk Lovingness}

Individuals may have different risk attitudes. Intuitively, risk aversion makes the closed envelope less attractive such that even under high monetary incentives, only very altruistic subjects prefer the closed envelope. The following figure demonstrates the case of $u(x)=\sqrt{x}$ for different levels of moral discounting, $\beta$. If the moral discounting is pronounced, even most selfish individuals prefer to leave the envelope closed in order to avoid moral costs from rejecting the donation.
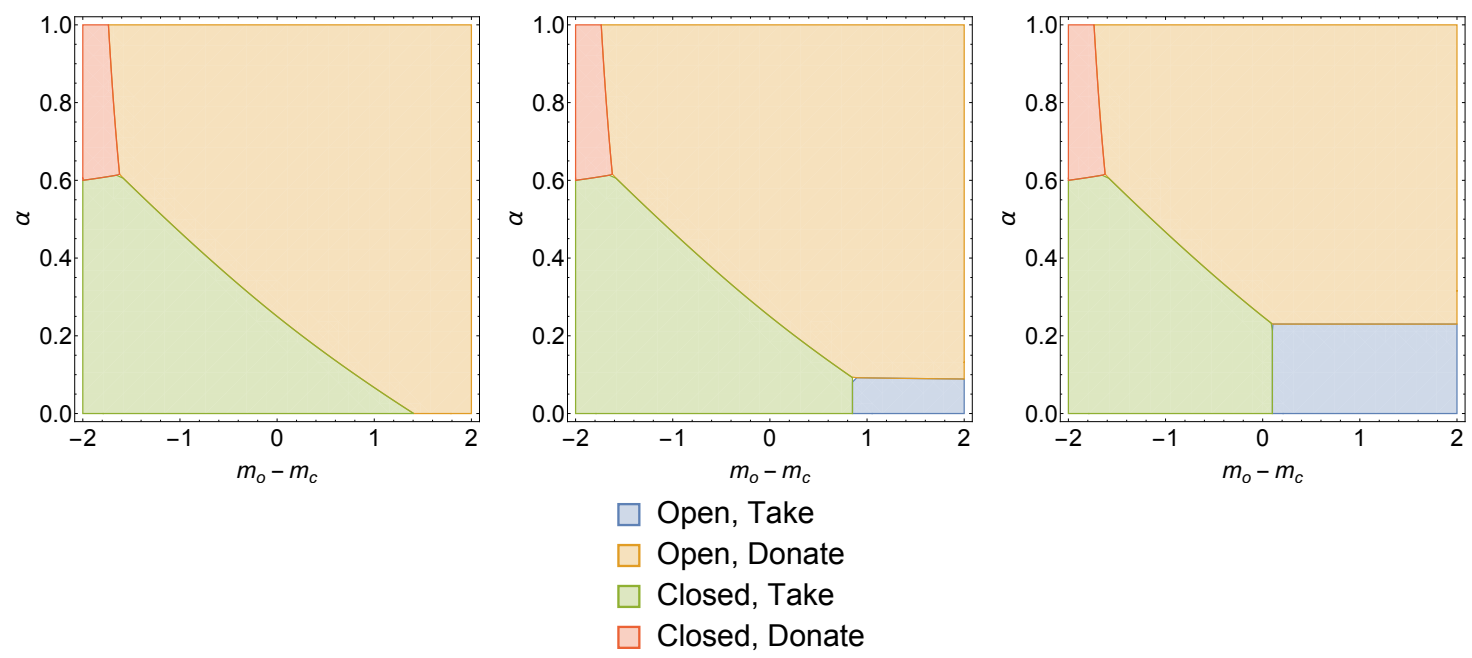

Figure C.1: Risk aversion: $u(x)=\sqrt{x} ; \beta=0.36,0.66,0.96$, respectively

In contrast, the closed envelope can become quite appealing for altruists if they are risk loving. The following figure illustrates that case.
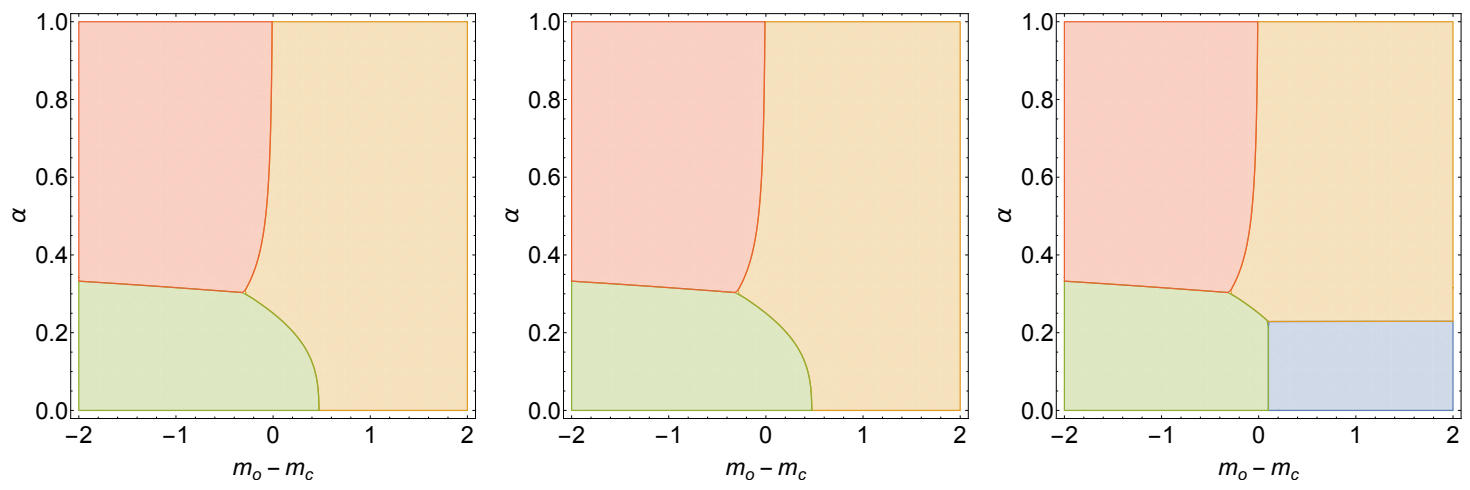

$$
\begin{aligned}
& \text { Open, Take } \\
& \text { Open, Donate } \\
& \text { Closed, Take } \\
& \text { Closed, Donate }
\end{aligned}
$$

Figure C.2: Risk loving: $u(x)=x^{4} ; \beta=0.36,0.66,0.96$, respectively 


\section{Working Paper Series in Economics}

recent issues

No. 120 Marta Serra-Garcia and Nora Szech: The (in)elasticity of moral ignorance, December 2018

No. 119 Thomas Mariotti, Nikolaus Schweizer, Nora Szech and Jonas von Wangenheim: Information nudges and self-control, November 2018

No. 118 Andranik S. Tangian: Methodological notes on composite indicators for monitoring working conditions, October 2018

No. 117 Andranik S. Tangian: Testing the improved third vote during the 2018 election of the Karlsruhe Institute of Technology student parliament, September 2018

No. 116 Yuri Golubev and Mher Safarian: On robust stopping times for detecting changes in distribution, May 2018

No. 115 Daniel Hoang, Sebastian Gatzer and Martin Ruckes: The economics of capital allocation in firms: Evidence from internal capital markets, January 2018

No. 114 Francesco D'Acunto, Daniel Hoang and Michael Weber: Unconventional fiscal policy, January 2018

No. 113 Alberto Bucci, Levent Eraydın, Moritz Müller: Dilution effects, population growth and economic growth under human capital accumulation and endogenous technological change, January 2018

No. 112 Jochen Schweikert and Markus Höchstötter: Epidemiological spreading of mortgage default, January 2018

No. 111 Armin Falk and Nora Szech: Diffusion of being pivotal and immoral outcomes, December 2017

No. 110 Leonie Kühl and Nora Szech: Physical distance and cooperativeness towards strangers, November 2017 